\title{
Uncovering Membrane-Bound Models of Coagulation Factors by Combined Experimental and Computational Approaches
}

\author{
Y. Zenmei Ohkubo ${ }^{1, *}$ Jesper J. Madsen $2, *(\infty)$ \\ ${ }^{1}$ Department of Bioinformatics, School of Life and Natural Sciences, \\ Abdullah Gül University, Kayseri, Turkey \\ ${ }^{2}$ Global and Planetary Health, College of Public Health, University of \\ South Florida, Tampa, Florida, United States \\ Thromb Haemost 2021;121:1122-1137.
}

\begin{abstract}
Address for correspondence Jesper J. Madsen, PhD, Global and Planetary Health, College of Public Health, University of South Florida, Tampa, FL 33612, United States (e-mail: jespermadsen@usf.edu).

Y. Zenmei Ohkubo, PhD, Department of Bioinformatics, School of Life and Natural Sciences, Abdullah Gül University, 38080 Kayseri, Turkey (e-mail: yzohkubo@gmail.com).
\end{abstract}

\author{
Abstract \\ Keywords \\ - coagulation factors \\ - complex formation \\ - membrane-bound \\ forms \\ - membrane lipids \\ - peripheral membrane \\ proteins \\ - phosphatidylserine \\ - tissue factor
}

In the life sciences, including hemostasis and thrombosis, methods of structural biology have become indispensable tools for shedding light on underlying mechanisms that govern complex biological processes. Advancements of the relatively young field of computational biology have matured to a point where it is increasingly recognized as trustworthy and useful, in part due to their high space-time resolution that is unparalleled by most experimental techniques to date. In concert with biochemical and biophysical approaches, computational studies have therefore proven time and again in recent years to be key assets in building or suggesting structural models for membrane-bound forms of coagulation factors and their supramolecular complexes on membrane surfaces where they are activated. Such endeavors and the proposed models arising from them are of fundamental importance in describing and understanding the molecular basis of hemostasis under both health and disease conditions. We summarize the body of work done in this important area of research to drive forward both experimental and computational studies toward new discoveries and potential future therapeutic strategies.

\section{Introduction}

Blood clotting is governed by a tightly regulated enzymatic cascade involving the coagulation factors in which the tiny amounts of the factors circulating, upon being triggered by trauma, amplify and control the physiological response. ${ }^{1-3}$ To elucidate the biochemical mechanisms for (in)activation of the coagulation cascade, specific or semi-specific interactions between coagulation proteins and membrane lipids need to be identified and characterized. ${ }^{4}$ The membrane surface serves as the functional platform for both colocal-

Equally contributed as corresponding co-authors.

received

May 18, 2020

accepted after revision

November 11, 2020

published online

July 2,2021 izing and (in)activating coagulation factors, and is as such an essential cofactor of central importance in aspects of activation, amplification, and regulation of the cascading reactions. ${ }^{5,6}$ Structural studies can provide unique insights into how exactly this is accomplished on the molecular level. Computational approaches, ${ }^{7-10}$ in particular, are apt for this purpose, providing dynamic features of the biomolecules involved, at unparalleled spatiotemporal resolution. Furthermore, computational approaches can show us the atomic details of both membrane-bound coagulants and the interacting membrane lipids, which essentially have not been achieved directly by any experimental method to date.
DOI https://doi.org/ $10.1055 / \mathrm{s}-0040-1722187$. ISSN 0340-6245.

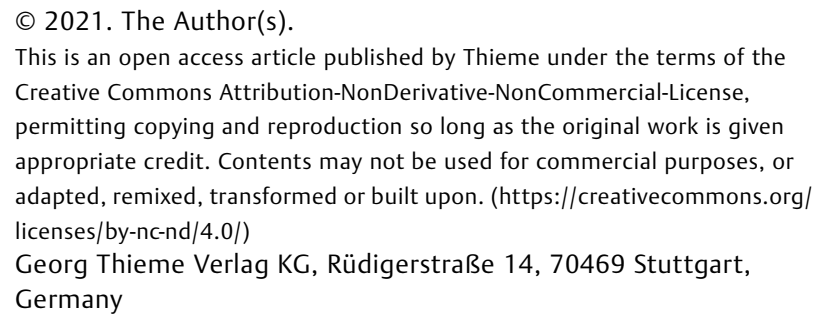


The technical term "computational approach" for investigating the molecular basis of the coagulation cascade usually refers to those approaches that employ in silico methodologies, such as docking, ${ }^{11}$ molecular dynamics (MD), ${ }^{12}$ ensemble refinement, ${ }^{13,14}$ and their variations combined with bioinformatics techniques when appropriate. It is important to acknowledge upfront that the computational approach relies critically on experimental observations in both requirement of initial coordinates of atoms of individual protein molecules and also restriction of the astronomical search space when setting the configuration of proteins in the systems to simulate. Suitable experimental techniques to elucidate structural and dynamic features of the coagulation cascade include site-directed mutagenesis, ${ }^{15-17}$ nanodisc, ${ }^{18,19}$ electron spin resonance, ${ }^{20}$ Förster resonance energy transfer (FRET), surface plasmon resonance, ${ }^{12,21}$ and cryogenic electron microscopy (cryo-EM), ${ }^{22}$ as well as recently developed X-ray reflectivity (XRR) ${ }^{23,24}$ and X-ray freeelectron laser. ${ }^{25}$ The combination of both experimental and computational approaches has proven particularly powerful as they complement each other exquisitely to uncover the detailed mechanisms in the coagulation cascade (in)activation. ${ }^{8,10,26-32}$

Accurate models for membrane-bound $\gamma$-carboxyglutamic acid rich (GLA) and C2 domains, which are the two most predominant entities that anchor coagulation factors to membrane surfaces, can be the key to further model the membrane-binding mode of the whole molecules, and then the complex formation with other (co)factors, dramatically reducing the search space for potential binding/docking orientations of coagulation proteins.

In this review, coagulation factors and relevant molecules are referred to as those of human's, unless otherwise specifically noted. The basic information on individual coagulants is found elsewhere, $22,33,34$ and this review focuses on summarizing membrane-bound forms of individual coagulants and their complexes on the membrane surface where they perform their physiological functions. Some emphasis is placed on disseminating foundational principles of state-of-the-art developments in theoretical and computational methods for the broad interest of nonexperts and potential future practitioners. It is our hope that this review will support further developments aiming to uncover the structural mechanisms that underlie hemostasis in health and disease.

\section{Molecular Dynamics Simulations}

\section{Advantages and Limitations of Molecular Dynamics Simulations}

MD is a computational microscope of atomic resolution. ${ }^{35}$

This imaginary microscope is compact and inexpensive; in general it requires a smaller space to install and less investment when compared with the experimental equipment/approaches, while allowing for observing the behaviors of individual molecules clearly, not only detecting the statistical trends averaged over numerous molecules. ${ }^{36,37}$ Biological processes, such as membrane binding of GLA domains as described in the following sections, can be observed repeatedly and consistently to reveal the molecular mechanisms with atomic details. In addition, it is readily possible in MD methodologies to alter or gradually change the conditions of systems of interest, such as the temperature, the pressure, $\mathrm{pH}$, and the molecular composition, which may be intractable or impossible in experimental approaches.

On the other hand, the wall times required by MD methodologies are far longer than the actual durations within which molecules of interest carry on certain collective motions. A few to some tens of nanoseconds-long molecular phenomena in nature may be simulated as a 1day-long MD job, depending on the system size, the force field used, and the computer resources employed. The success of an MD simulation therefore relies both on the accessible time scales and availability of the initial coordinates for the system, which is often built as a mixture of smaller molecules (i.e., water, lipids, ligands, and/or ions) and proteins whose structures are based on specific Protein Data Bank ${ }^{38}$ (PDB) entries.

It should be noted that the coordinates of most PDB entries are determined by either X-ray crystallography or by nuclear magnetic resonance (NMR), often under nonphysiological conditions (e.g., very high protein and/or salt concentrations, low temperature), and that the obtained structures of such proteins may not represent their physiological conformations as a whole or in part (and there exists no simple way to assess the differences). Or there may be several physiologically important conformations for a flexible protein, while a PDB structure of the protein represents just one of them. Such potential cases include $1 \mathrm{DAN}^{39}$ and $1 \mathrm{PFX}{ }^{40}$ for GLA domaincontaining coagulation factors, which share the same topology except the relative positioning of GLA and epidermal growth factor-like domain 1 (EGF1) domains, as well as $1 \mathrm{QFK},{ }^{41}$ which indicates that there could be a rearrangement of EGF1 and EGF2 upon binding to tissue factor (TF). Factor VII (FVII), factor IX (FIX), or factor X (FX) as well as prothrombin (PT) may be in either topology, in its (in)active and/or complex/free form, depending on the environment.

If a PDB entry unfortunately does not quite represent an appropriate physiological structure of the protein under the physiologic condition of choice, the systems including the protein require a long equilibration in advance of meaningful MD simulations, hoping the protein will reach its physiological conformation, or the equilibration trial itself may be a wild goose chase and one may not even notice such a situation. Hence, extensive validation using all available experimentally obtained structural information is critical for successful application of MD simulations.

\section{Force Fields}

There are three things needed to perform MD methodologies: initial atomic coordinates of the system of interest (i.e., the molecules to simulate), an MD package and a set of force field, and the computer on which the MD of the system is performed, using the force field. ${ }^{36,37}$ Several sets of MD packages with associated websites that include the manuals and tutorials have been available either for free or at 
reasonable costs, ${ }^{42}$ such as AMBER, ${ }^{43}$ CHARMM, ${ }^{44}$ GROMACS, ${ }^{45}$ NAMD, ${ }^{46}$ and Tinker $^{47}$ that have been commonly used for MDs of biomolecules including proteins and lipids, as well as rather recently developed OpenMM ${ }^{48}$ and GENESIS. ${ }^{49}$ Most of these packages implement their own force field (see the next section for details) of the same name as well as several other force fields including OPLS. ${ }^{50}$

A typical potential energy function for MD at the atomic scale can be formulated as shown in Eq. $1:^{36,37,51,52}$

$$
\begin{aligned}
V & =\sum_{\text {bonds }} K_{b}\left(b-b_{0}\right)^{2}+\sum_{\begin{array}{c}
\text { bond } \\
\text { angles }
\end{array}} K_{\theta}\left(\theta-\theta_{0}\right)^{2} \\
& +\underset{\substack{\text { dihedral } \\
\text { angles }}}{\sum} K_{\phi}[1+\cos (n \phi-\delta)]+\sum_{\begin{array}{c}
\text { nonbonded } \\
i, j \text { pairs }
\end{array}}^{\sum}\left[\frac{A_{i, j}}{r_{i, j}{ }^{2}}-\frac{B_{i, j}}{r_{i, j}{ }^{6}}+\frac{q_{i} q_{j}}{r_{i, j}}\right]
\end{aligned}
$$

which defines empirical distance-dependent, pairwise-additive interactions among atoms under the Born-Oppenheimer approximation (which results in the assumption that the average position of the electrons of an atom matches that of the nucleus -or the treatment that atomic charges are located upon the positions of the atoms). The first summation is of any pair of atoms in the system that are covalently bonded as a simple harmonic potential form, where $b$ is the observed bond length, $2 K_{b}$ is the spring constant of Hooke's law for the bonded atom pair, and $b_{0}$ is the standard bond length of the atom pair. The second summation is a superposition of any bond angle vibration onto harmonic potentials, where $\theta, 2 K_{\theta}$, and $\theta_{0}$ are the observed bond angle of any linearly bonded three atoms, the angle bending spring constant, and the bond angle at equilibrium of the atom triplet, respectively. The third sum is over any torsion angle, where $\phi, K_{\phi}, n$, and $\delta$ are a dihedral angle, the force constant of the angle, multiplicity for the hindered rotation, and the phase to specify the equilibrium rotation angles, respectively.

The above three sums are for bonded atoms, whereas the last is for any pair of two nonbonded atoms, $i$ and $j$, that are separated at least four (or three in some force fields) bonds, assuming the interactions between atoms within three bonds are handled accurately enough by the first three sums. The three terms in the fourth sum represent Pauli core repulsion, van der Waals dispersion (two terms collectively, Lennard-Jones interactions), and Coulombic interactions, where $r_{i, j}, q_{i}, q_{j}$, and $\varepsilon$ are the distance between atoms $i$ and $j$, the effective partial charge of atom $i$, that of atom $j$, and a dielectric parameter (often set at or around 2 for inside proteins), respectively. $A_{i, j}$ and $B_{i, j}$ are Lennard-Jones constants, from which the minimum of the Lennard-Jones interaction between atoms $i$ and $j$ is given as $-B_{i, j}^{2} / 4 A_{i, j}$ at the distance of $\sqrt[6]{2 A_{i, j} / B_{i, j}}$.

The formulation is rather heuristic for simplicity and therefore fast computation, especially for dihedral angles that is purely an adjustment term, while the last two terms (dispersion and Coulombic interactions) are physics-based. Yet, this type of force fields with the parameters determined from quantum-mechanical calculation or experiments of smaller molecules provides decent accuracy for exploring biological phenomena except for those that take place in the environments of very high temperature or pressure.

\section{Computing MD Simulations}

MD computation is repeated numerical integration of the classical Newton's equation of motion. The most commonly used method is the so-called velocity Verlet algorithm. ${ }^{53} \mathrm{By}$ differentiating $V_{i}\left(r_{i}, t\right)$ of Eq. $1(r, i$, and $t$ are added to refer to the coordinate $r$ of any atom $i$ in a system of interest at the current time $t), F_{i}\left(r_{i}, t\right)$, the current force on atom $i$, can be obtained. Then using $r_{i}(t), F_{i}\left(r_{i}, t\right)$, and $F_{i}\left(r_{i}, t-\Delta t\right)$, the future position of atom $i, r_{i}(t+\Delta t)$, can be obtained as follows:

$$
v_{i}(t)=v_{i}(t-\Delta t)+\frac{\Delta t}{m_{i}} \frac{F_{i}\left(r_{i}, t\right)-F_{i}\left(r_{i}, t-\Delta t\right)}{2}
$$

$$
r_{i}(t+\Delta t)=r_{i}(t)+\Delta t v_{i}(t)+\frac{\Delta t^{2}}{2 m_{i}} F_{i}\left(r_{i}, t\right)
$$

where $m_{i}$ is the mass of atom $i, \Delta t$ is a short duration, and $v_{i}$ is the velocity of atom $i$, safely assuming that $F_{i}$ is constant within a very short time of $\Delta t$. By setting the initial coordinate $r_{i}$ and the initial velocity $v_{i}$ (by specifying the temperature), the set of the equations (Eqs. 2 and 3) can be repeatedly updated, providing the time development of all atoms in the system. The length of $\Delta t$, however, needs to be shorter than the cycles of the fastest motions of atoms (i.e., the hydrogeninvolved bond length vibrations) for accurate integration. Therefore $\Delta t$ is typically set at some femtoseconds, which results in millions of cycle updates of Eqs. 2 and 3 to simulate for a length of some nanoseconds.

\section{Running MD Software Packages}

Since the potential energy function is in a pairwise form (Eq. 1), the computation time required for updating Eq. 2 and 3 once should be proportional to the squared number of atoms in the simulation system, provided the same computer and if implemented naïvely. However, by using interaction cutoff criteria and handling long-range electrostatics with more sophisticated methods (multigrid or fast Fourier transform), the actual computation time for a unit cell (a system to simulate) with edges of several nanometers or longer is approximately proportional to the number of particles (i.e., atoms or "coarse-grained" atoms-see the next section). The typical system of coagulants and a patch of cell membrane would include over a quarter of million particles. Several tens of nanoseconds-long MD may be simulated per day for such a system by a graphics processing unit (GPU)-equipped computer, which is an acceptable computation rate for the purpose (although an even faster rate is always desirable).

One can relatively easily prepare a system to simulate ${ }^{54}$ and run MD jobs of the system by either obtaining an account at a high-performance computing center, a computing cloud, or purchasing a server equipped with multiple, fast central processing units, a few gigabytes of random-access memories, and a GPU or two. Note also that the GPU does not have to be a high-end model. A several times-inexpensive so- 
called "gamers model" will perform nearly the same for MD computation.

Running an MD program for a system of interest generates the trajectory files that log the coordinates of the atoms in the system as a function of time. Visualization software such as PyMOL, ${ }^{55}$ UCSF Chimera, ${ }^{56}$ and VMD $^{57}$ can convert the trajectories into movie files, using a wide variety of atom representations. The moving images in such files, often shown in oral presentations or available at the journal Web sites, are like slow-motion films; events within the scale of submicroseconds are presented in some tens of seconds. In such "MD films," the fastest local vibrational motions of individual atoms, which are the majority of the whole internal degrees of freedom in case for proteins, ${ }^{58}$ are customarily removed (and often without mentioning so) by time-averaging the coordinates of the atoms, because such local fluctuations are usually irrelevant compared with slower, nonlocal conformation changes that can be observed clearly by cancelling local vibrations.

\section{Models for Membranes}

To accelerate the computation rate, ${ }^{42,59}$ different membrane models and associated force fields have been developed for different purposes. ${ }^{60}$ One obvious approach is to reduce the number of particles in a system by representing a group of atoms by a "coarse-grained" particle and employing dedicated force fields (e.g., MARTINI ${ }^{61}$ ), sacrificing the atomic level of resolution. Furthermore, multiscale modeling and simulation methodologies ${ }^{62,63}$ combine the advantages of both atomic and coarse-grained scales, (re-)mapping a system of interest from one scale to the other. ${ }^{64-66}$

Another dimension to explore is to represent (a part of) the membrane with smaller molecules that keep relevant characteristics, which will accelerate desired transitions in the system, ${ }^{67,68}$ sustaining the atomic resolution while having the system size basically unchanged. The highly mobile membrane-mimetic model ${ }^{67}$ (HMMM) is particularly suitable to simulate membrane binding of coagulants and their complex formations on the membrane. In HMMM, membrane lipids are selectively fragmented; in other words, tip parts of long acyl tails are replaced by small organic molecules of similar chemical properties. As a result, the diffusion and local fluctuations of the membrane lipids are significantly augmented, which enables membrane binding of peripheral membrane proteins within accessible computation scale by current computer processing standards.

\section{Models for the Membrane-Binding Domains}

\section{GLA Domain}

The GLA domain is one of the major membrane-binding structural motifs for coagulation factors. Since the structure of an activated FVII-TF (FVIIa-TF; "a” for activated, “_” for complex, same for other factors) complex was solved by X-ray crystallography, ${ }^{39}$ several models for the membrane-bound GLA domain have been proposed over the years. Due to seven linearly bound calcium ions, most of which can interact with anionic membrane lipid headgroups, the proposed models are largely in agreement on the domain's orientation with respect to the membrane. The membrane insertion depth of GLA domains, however, remains in disagreement. The difference seems to originate from the consideration of the balance of electrostatic and hydrophobic interactions between the GLA domain and the membrane. ${ }^{39}$

The first pilot model for the FVII GLA domain ${ }^{69}$ (tagged as "St. Paul-1999" in - Table 1) was proposed as having the $\omega$ loop and the $\mathrm{K} 32$ residue being located on the surface of the membrane and the line intersecting bound calcium ions being slanted to the membrane surface ( $\mathbf{- F i g . 1}$ ). The model is based on the observations that bound calcium ions and GLA residues are mostly not in contact with the membrane and that the protein-membrane interactions are primarily hydrophobic. ${ }^{39,70}$ This model and none other employs a GLA domain orientation with an oblique calcium line. Later studies reported such positioning was observed during $\mathrm{MD}^{9,67}$ and it was suggested that the model might be of a binding intermediate, ${ }^{9,67}$ rather than the final equilibrium orientation.

The membrane-bound form of the FX GLA domain was proposed $^{71}$ ("Kiyose-2001" in - Table 1), based on the crystal structure of the FX GLA domain bound by an anticoagulant, hundred-pacer snake's venom. In this model, protruded hydrophobic residues at the tip of the $\omega$-loop, namely F4, $\mathrm{L} 5$, and $\mathrm{V} 8$, penetrate the membrane and the calcium line is about level above the membrane. This arrangement is essentially identical to another model for the PT GLA domain mutant as F4W 72 ("Boston-2001"). An equivalent model was also suggested for the bovine PT (bPT) GLA domain ("Boston2003"), using the NMR-solved structure of the bPT GLA domain bound by a lysophosphatidylserine ${ }^{73}$ (lysoPS). Yet another equivalent model was proposed for the FIX GLA domain, relying upon NMR study of an octapeptide that mimicked the FIX $\omega$-loop. ${ }^{74}$

A later MD study 9 ("Urbana-2008"), however, reported that the outer four of the bound calcium ions can interact with membrane lipid phosphatidylserine (PS) headgroups and that the membrane penetration depth of the GLA domain is approximately $1.2 \mathrm{~nm}$ deeper than other models while the orientations of the domains are equivalent (-Fig. 1). This model was further supported by a repeatedly observed membrane-binding process, using a mobility-augmented membrane model named HMMM. ${ }^{67}$ It was also reported that the GLA domain positioning with a slanted calcium line on the membrane surface ${ }^{69}$ was often observed during MD as if it were a possible binding intermediate., ${ }^{9,67}$ The Urbana-2008 model served as the basis of a novel explanation for the membrane-GLA domain interaction as "single PS-specific interaction and multiple phosphate-specific interactions," or in short, the "Anything But Choline" (ABC) hypothesis. ${ }^{30}$

Monitoring the membrane binding of GLA domains to anionic membranes is possible by solid-state $\mathrm{NMR}^{29}$ (SSNMR) or XRR ${ }^{23,24}$ to compare the results with the models proposed; the bound divalent calcium ions may be problematic for SSNMR, but not for XRR. Experts' trials are highly anticipated, because finding the actual positioning of the 


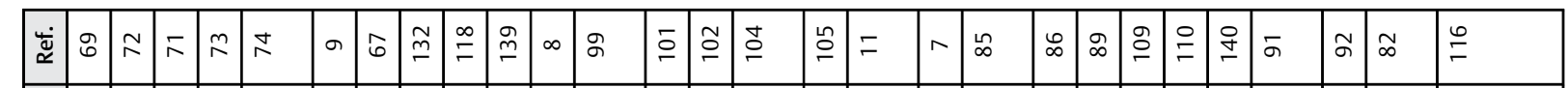

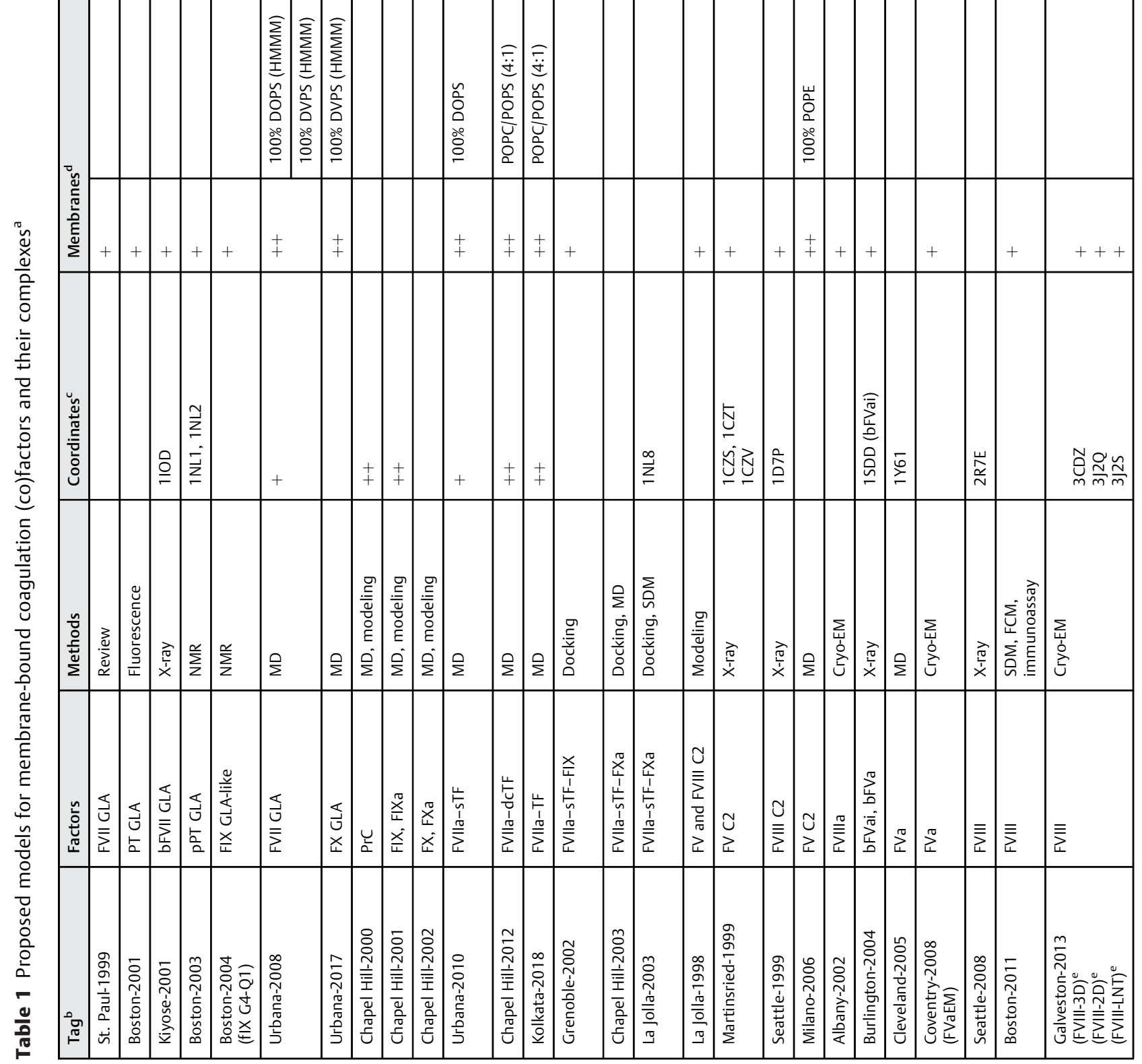




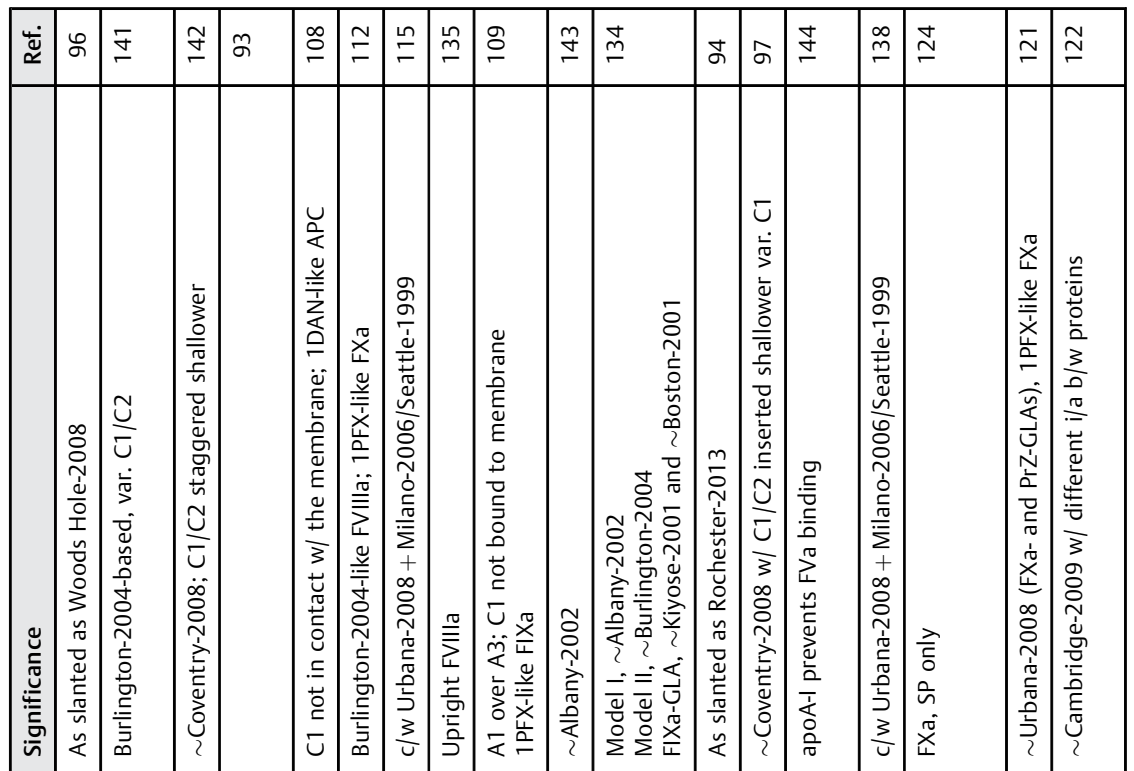
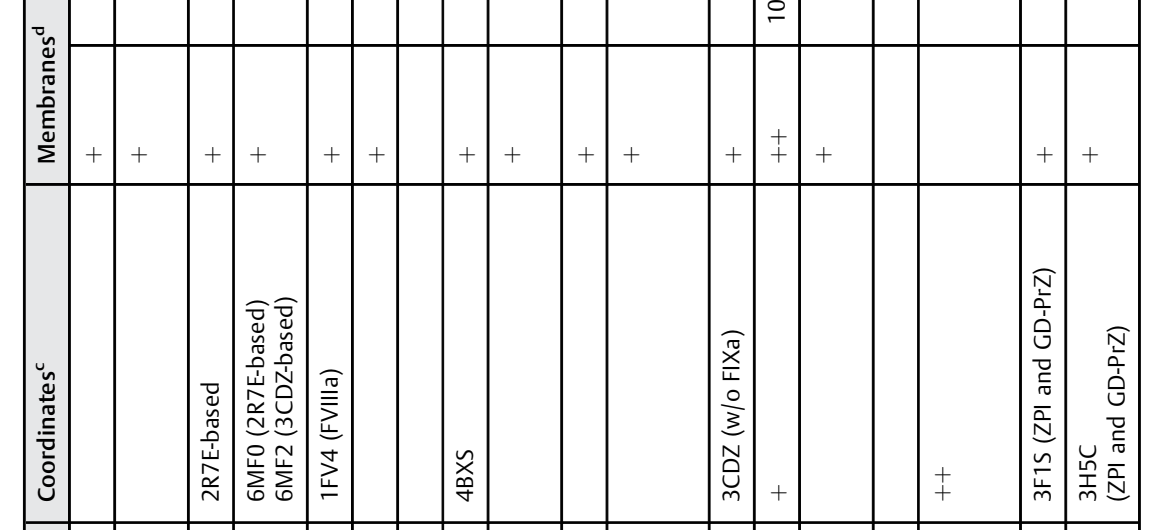

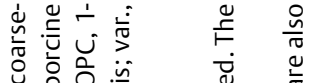

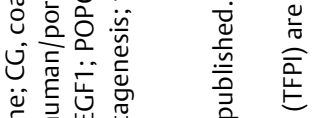

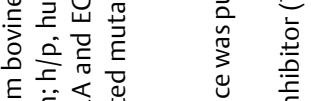

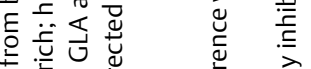

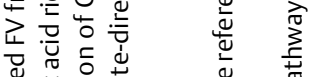

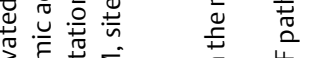

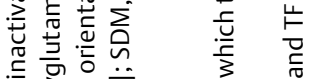

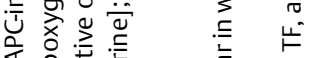

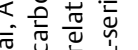

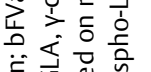

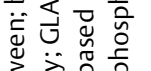
妾 वे

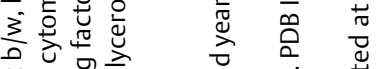

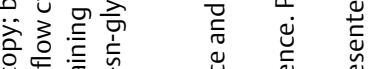

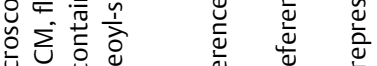

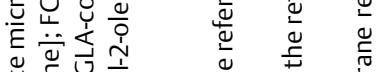

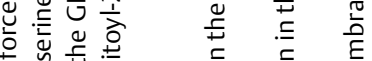
है

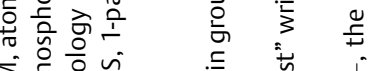

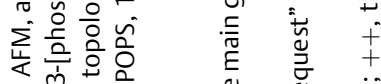

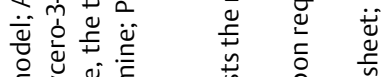

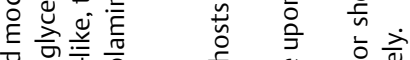

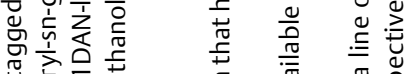

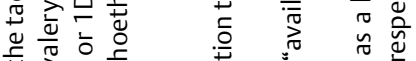

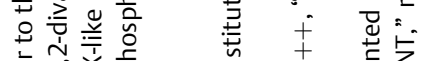
는

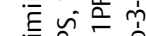
员守

व है들

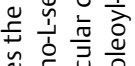

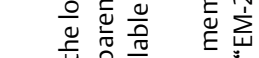

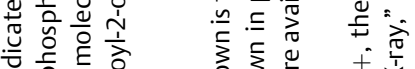

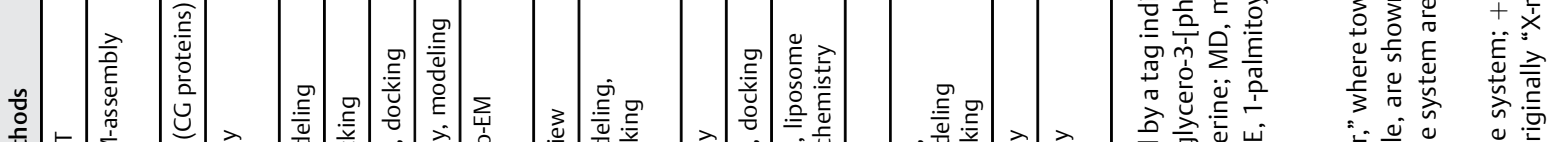

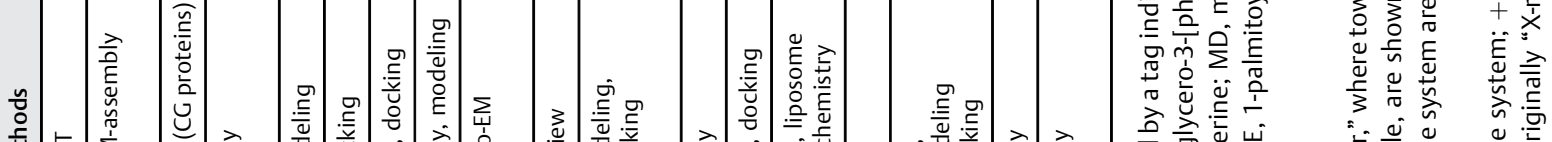

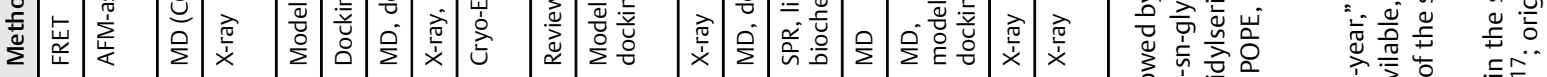

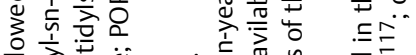

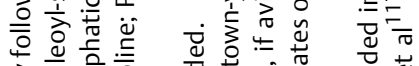

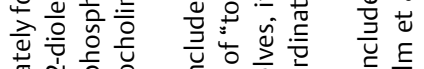

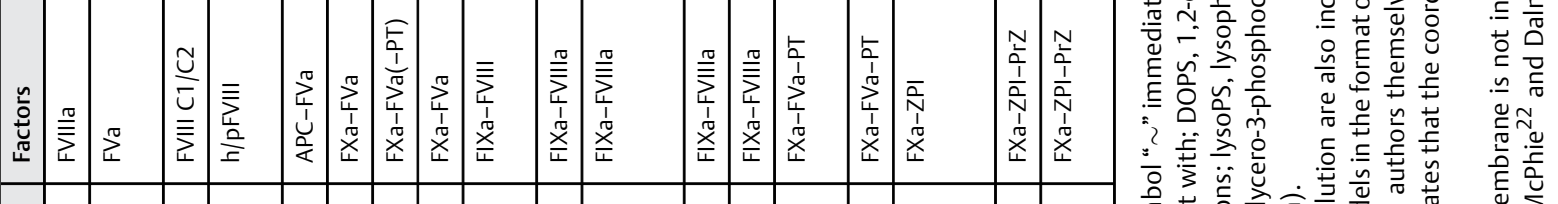

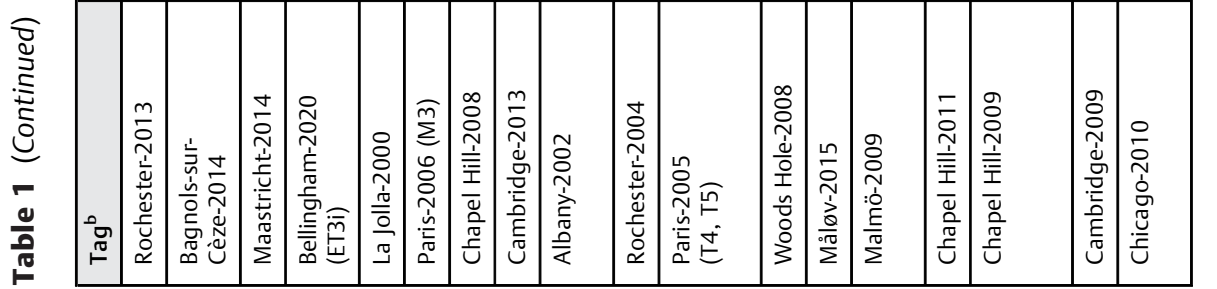

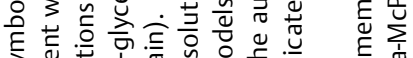

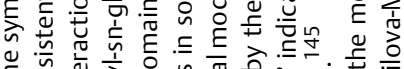

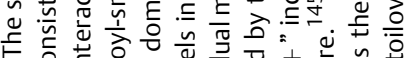

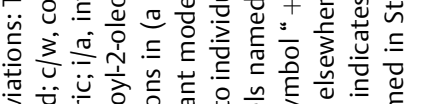

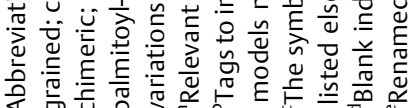



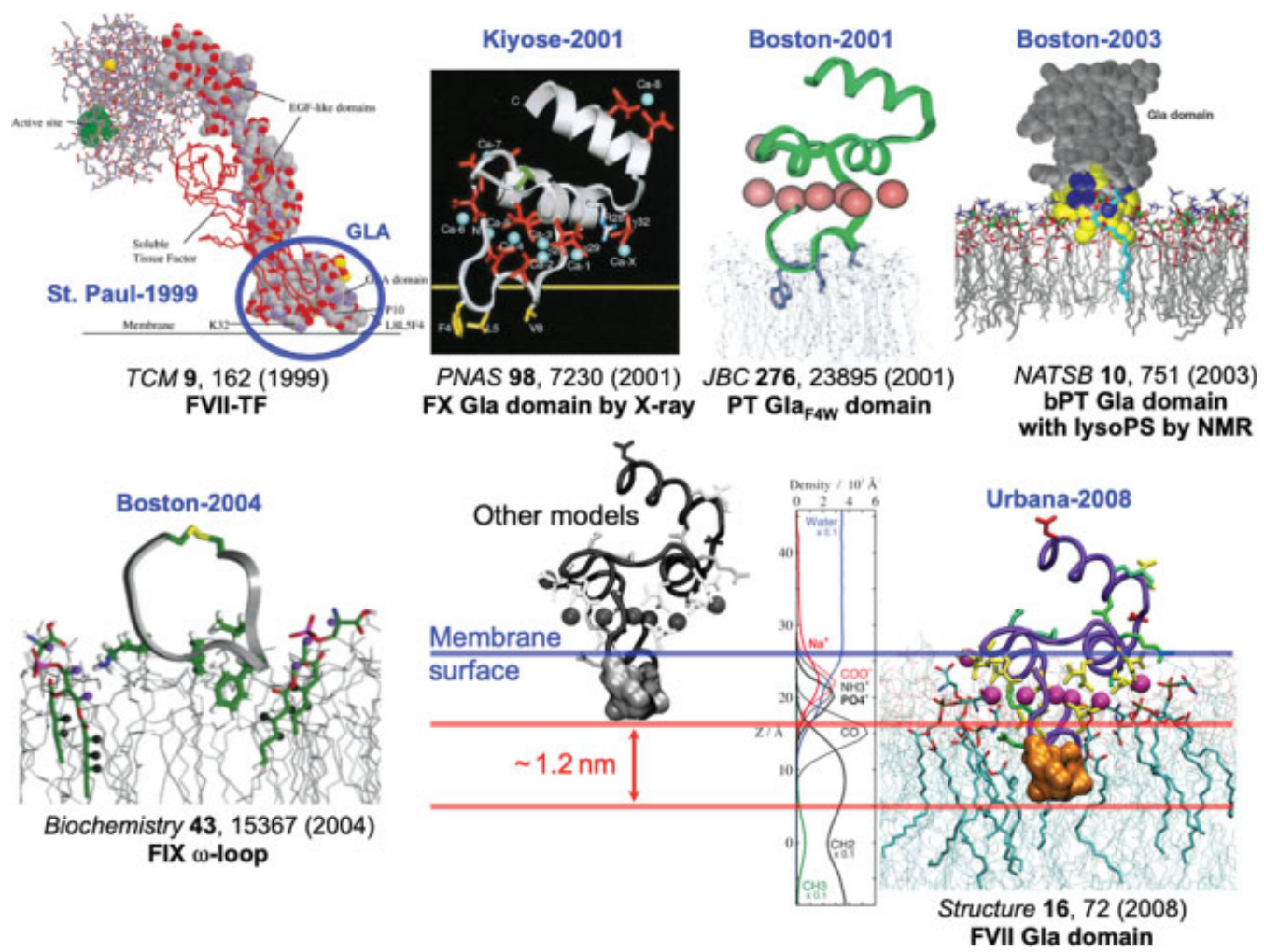

Fig. 1 Models for membrane-bound GLA domains. The insertion depth of the model "Urbana-2008" 9 is $\sim 1.2$ nm deeper than other models. "St. Paul-1999," ${ }^{69}$ in which the outermost $\mathrm{Ca}^{2+}$ ion of the calcium line and the basic residues nearby are close to the membrane surface, was observed during MDs in Ohkubo and Tajkhorshid. ${ }^{9}$ Individual figures are adapted from Nelsestuen, ${ }^{69}$ Mizuno et al (Copyright (2001) National Academy of

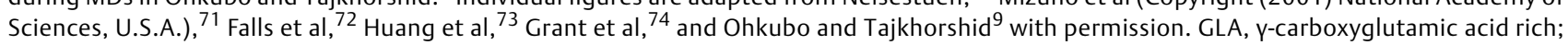
MDs, molecular dynamics.

GLA domain with respect to the membrane, as well as that of the catalytic triad (CT) and substrate (-Table 2 ), reduces sterically possible arrangement of neighboring domains, and therefore leads to further modeling the whole molecules and complexes on the surface of the membrane, excluding the otherwise possible vast majority of the potential arrangement candidates.

\section{C1/C2 Domains}

C2 and C2-like domains ${ }^{33,75}$ are another major family of membrane-binding sites of coagulation factors. In this review "C2-like domains" refers only to the extracellular phospholipid-binding discoidin domains of certain coagulation factors. ${ }^{76}$ We note that there are other domains also referred to as "C2-like" such as lactadherin ${ }^{77-79}$ and PKC $\alpha$ class C2 domains. ${ }^{80,81}$ Factor V (FV) and FVIII include homologous $\mathrm{C} 1$ and $\mathrm{C} 2$ domains that individually have membranebinding properties and facilitate cofactor membrane binding. Curiously, there is nontrivial interplay and cooperation between the domains in determining the precise binding kinetics and lipid component specificity for the full-length cofactors. $^{82-84}$ The structures of FV and FVIII C2 domains were solved by X-ray crystallography ${ }^{85,86}$ as an eight-stranded Greek-key topology $\beta$-barrel with moderately long hairpins, or spikes (or "fatty feet" ${ }^{87}$ ) at the bottom (the opposite side of $\mathrm{N}$ - and C-terminal ends). These spikes include hydrophobic residues toward the tips, and it is suggested that $\mathrm{C} 2$ domains bind to membrane surfaces facilitated by these spikes, while a few other strategically placed basic residues interact with anionic headgroups of the membrane lipids, yielding $\mathrm{Ca}^{2+}$-independent stereospecific recognition toward PS lipids. ${ }^{85}$ Based on these considerations, and the domain surface hydrophobicity distribution, a slightly tilted $\beta$-barrel, where the domain leans toward one side on the membrane, was suggested as the membrane-bound form of the FVIII C2 domain ${ }^{85}$ ("Martinsried-1999," "Seattle-1999" in -Table 1; - Fig. 2). A similar form would be expected for the FV C2 domain. Alanine-scanning mutagenesis on the FV C2 domain also indicated the spikes as the membranebinding sites. ${ }^{88}$ Since then, several models for membranebound forms of $\mathrm{C} 2$ (and/or C1) domains have been suggested. They are however at variance in the insertion depth and/or the orientation of the domains with respect to the membrane (-Fig. 2).

Before the structures of $\mathrm{C} 2$ domains became available, the first models for membrane-bound FV and FVIII C2 domains were proposed, based on the results of threading their sequences through the known structure of a fungal galactose oxidase-binding domain ${ }^{7}$ (the $\beta$-barrel is upright with respect to the membrane; "La Jolla-1998" in - Table 1). Later, an MD study showed that the FVa C2 domain autonomously bound neutral 1-palmitoyl-2-oleoyl-sn-glycero-3-phosphoethanolamine (POPE) membrane with a part of the $\beta$ barrel buried into the membrane and the axis of the barrel nearly aligned with the membrane normal ${ }^{89}$ similarly to La Jolla-1998 (the barrel is upright with respect to the 
Table 2 Average height of CT from the membrane surface by experimental and computational measurements

\begin{tabular}{|c|c|c|c|c|c|}
\hline Coagulant(s) & Environment & FRET donor group at CT & Methods & $\begin{array}{l}\text { CT height/nm } \\
\text { Mean (SD) }\end{array}$ & Ref. \\
\hline FVIIa & PC/PS (4:1) vesicles & FI-FPR & FRET & - & 136 \\
\hline FVIla-dcTF & PC/PS/PE (56:6:40) vesicles & Fl-FPR & FRET & $7.7(0.2)$ & 136 \\
\hline FVIIa & PC/PS (4:1) vesicles & Fl-FPR & FRET & $8.31(0.33)^{a}$ & 137 \\
\hline FVIla-dcTF & PC/PS/PE (56:6:40) vesicles & Fl-FPR & FRET & $7.50(0.18)^{\mathrm{a}}$ & 137 \\
\hline GD-FVIIa-TF & PC/PS (4:1) vesicles & Fl-FPR & FRET & $7.80(0.18)$ & 137 \\
\hline FVIIa & In aqua & - & $\mathrm{MD}$ & $\sim 8.3^{\mathrm{b}}$ & 146 \\
\hline FVIla-sTF & In aqua & - & MD & $\sim 7.5^{\mathrm{b}}$ & 146 \\
\hline FVIla-dcTF & PC/PS (4:1) vesicles & Fl-FPR & FRET & $7.6(0.3)$ & 147 \\
\hline FVIIa & PS bilayer patch & - & MD & $8.51(0.38)^{c}$ & 99 \\
\hline FVIIa-sTF & PS bilayer patch & - & MD & $8.81(0.14)^{c}$ & 99 \\
\hline FVIla-dcTF & PC/PS (4:1) bilayer patch & - & MD (AMBER) & $7.796(0.158)^{d}$ & 101 \\
\hline FVIla-dcTF & PC/PS (4:1) bilayer patch & - & MD (NAMD) & $7.686(0.222)^{d}$ & 101 \\
\hline FVIIa & PC/PS (4:1) bilayer patch & - & MD & $7.704(0.257)$ & 102 \\
\hline FVIIa-TF & PC/PS (4:1) bilayer patch & - & MD & $8.497(0.069)$ & 102 \\
\hline FIXa-FVIIIa & PC/PS (4:1) vesicles & Fl-A-FPR & FRET & $8.9(0.3)$ & 148 \\
\hline FIXa & PC/PS (4:1) vesicles & FI-A-FPR & FRET & $8.9(0.3)$ & 148 \\
\hline FIXa-FVIIIa & PC/PS (4:1) vesicles & DEGR & FRET & $7.3(0.4)$ & 148 \\
\hline FXa & PC/PS vesicles & DEGR & FRET & $6.1(0.2)$ & 149 \\
\hline FXa-FVa & PC/PS vesicles & DEGR & FRET & $6.9(0.5)$ & 149 \\
\hline FXa & PC/PS (4:1) vesicles & Fl-A-FPR & FRET & $8.4(0.3)$ & 148 \\
\hline FXa & PC/PS (4:1) vesicles & Fl-FPR & FRET & $7.2(0.2)$ & 150 \\
\hline FXa-FVa & PC/PS (4:1) vesicles & FI-FPR & FRET & $7.5(0.1)$ & 150 \\
\hline FXa (desEGF1) & PC/PS (4:1) vesicles & Fl-FPR & FRET & $5.6(0.1)$ & 150 \\
\hline FXa-FVa (desEGF1) & PC/PS (4:1) vesicles & Fl-FPR & FRET & $6.3(0.1)$ & 150 \\
\hline FXa (S195C in SP) & PC/PS (4:1) vesicles & $\mathrm{Fl}-\mathrm{C} 195$ & FRET & $9.5(0.6)$ & 150 \\
\hline FX (S195C in SP) & PC/PS (4:1) vesicles & $\mathrm{Fl}-\mathrm{C} 195$ & FRET & $9.7(0.2)$ & 150 \\
\hline APC & PC/PS (4:1) vesicles w/o PrS & Fl-FPR & FRET & $9.4(0.4)$ & 119 \\
\hline APC & PC/PS (4:1) vesicles $w / \operatorname{PrS}$ & Fl-FPR & FRET & $8.4(0.4)$ & 119 \\
\hline APC & PC/PS (4:1) vesicles & Fl-FPR & FRET & $9.43(0.40)$ & 120 \\
\hline $\operatorname{PrC}$ & In aqua & - & MD & $\sim 8.9^{\mathrm{e}}$ & 118 \\
\hline MT-FVa & PC/PS (4:1) vesicles & DEGR & FRET & $7.1(0.2)$ & 123 \\
\hline MT & PC/PS (4:1) vesicles & DEGR & FRET & $6.7(0.3)$ & 123 \\
\hline
\end{tabular}

Abbreviations: APC, activated protein C; DEGR, dansyl-Glu-Gly-Arg; EGF1, epidermal growth factor-like domain 1; Fl-A-FPR, No-(2-mercaptoacetyl)FPR; FI-FPR, fluorescein-(D-Phe)-Pro-Arg; FRET, Förster resonance energy transfer; GD-FVIla, GLA domainless FVIla; GLA, y-carboxyglutamic acid rich; MD, molecular dynamics; MT, meizothrombin; PC, phosphatidylcholine; PE, phosphatidylethanolamine; PrC, protein C; PrS, protein S; PS, phosphatidylserine; sTF, soluble tissue factor; TF, tissue factor.

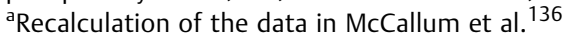

${ }^{b}$ Distance between C $\alpha$ of S195 in SP and N of L5 in GLA.

'Height of C $\alpha$ 's of CT from carboxy O's in PS headgroups.

${ }^{\mathrm{d} D i s t a n c e}$ between $\mathrm{C} \alpha$ of S195 in SP and the nearest P of PC or PS.

eHeight of CT from GLA-bound $\mathrm{Ca}^{2+}$ ions.

membrane; "Milano-2006" in - Table 1). Furthermore, it was reported that the FVa C2 domain exhibited conformational changes upon membrane binding, including significant orientational changes of the side chains of W26 and W27 residing in the first spike. This conformational change between what has been called the "open" and the "closed" forms of FV C2 domain was investigated in another study by means of free-energy calculations. ${ }^{90}$ It was found that while 


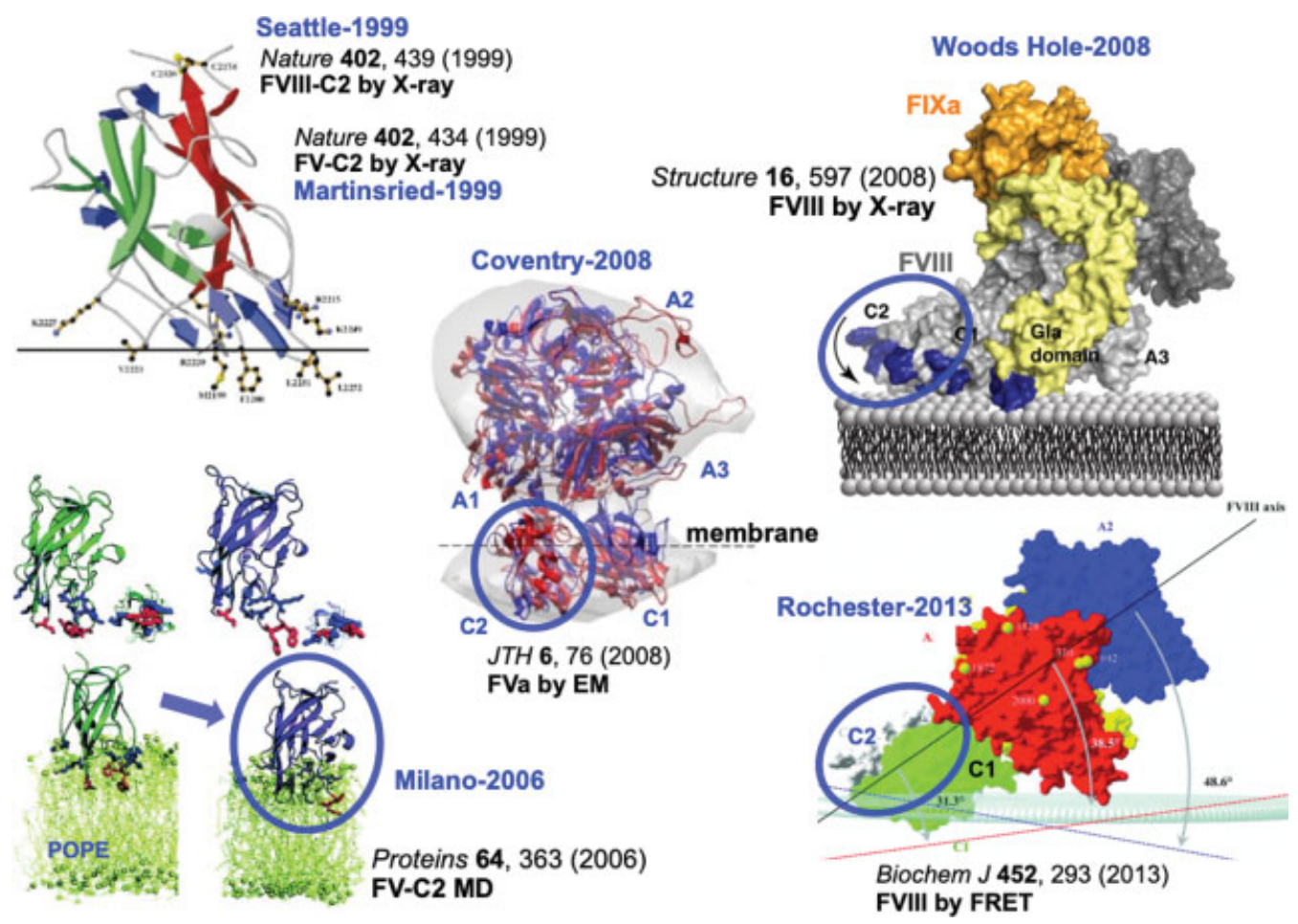

Fig. 2 Models for membrane-bound C2 domains of FV and FVIII. The orientations of the C2 domain with respect to the membrane in "Woods Hole-2008" 94 and "Rochester-2015"96 are consistent with each other, being significantly more slanted than those in other models. Among the other models, the C2 domain in "Coventry-2008" 91 is more than half buried in the membrane, while the upright orientation of the C2 domain against the membrane remains the same. Individual figures are adapted from Pratt et al, ${ }^{86}$ Mollica et al, ${ }^{89}$ Stoilova-McPhie et al, ${ }^{91} \mathrm{Ngo}$ et al, ${ }^{94}$ and Wakabayashi and Fay ${ }^{96}$ with permission.

rearranging W26 and W27 from the "open" to the "closed" form required the concerted motions of several spike residues, the stability of each state was comparable and only a low transition barrier $(\sim 1.5 \mathrm{kcal} / \mathrm{mol})$ separated the two states. A cryo-EM study ${ }^{91}$ of the nanotube-bound FVa C2 domain suggested a model for the membrane-bound FVa C2 domain, which is different from the above two in the insertion depth of the $\beta$-barrel (-Fig. 2). The model proposes upright, more-than-half buried $\beta$-barrels of juxtaposed C1 and C2 domains ("Coventry-2008").

Solving the FVIII structure by X-ray crystallography $92-95$ and by docking it with porcine FIXa (pFIXa), the binary complex of FVIIIa and FIXa was built ${ }^{94}$ ("Woods Hole2008"), in conjunction with a membrane-bound GLA domain model $^{73}$ to position FIXa. In this model, juxtaposed C1 and C2 domains lie on the membrane surface without inserting their spikes into the membrane. A model based on FRET ${ }^{96}$ measurement is in accordance with that by FIXa-FVIIIa docking. The angle between the membrane surface and that spanned by the centers of the individual domains of FVIIIa ranges between $30^{\circ}$ and $50^{\circ}$ with the $\mathrm{A} 3$ domain being in contact with the membrane surface. In a recent MD study ${ }^{97}$ ("Måløv2015"), multiple spontaneous binding events of FVIII to a PS HMMM membrane by the $\mathrm{C} 1$ and $\mathrm{C} 2$ domains were reported. The observed membrane binding modes of $\mathrm{C} 1$ and $\mathrm{C} 2$ domains were consistent, keeping their $\beta$-barrels close to juxtaposed and upright (or slightly tilted) toward the membrane, with more fluctuations in domain tilt for the $\mathrm{C} 1$ domain. Based on individual $\mathrm{C} 1 / \mathrm{C} 2$ domain membrane ori- entations (and assuming negligible domain rearrangement in FVIIIa), putative models of the FIXa-FVIIIa tenase complex were proposed. From those results, it was concluded that likely the $\mathrm{C} 1$ (and not $\mathrm{C} 2$ ) domain is primarily responsible for directing the membrane-bound orientation of the putative FIXa-FVIIIa tenase complex, since those models where generally consistent with the requirement that the FIXa GLA domain is known to be membrane-bound as well. Deep insertion of either $\mathrm{C} 1 / \mathrm{C} 2$ domain or tilted whole FVIIIa was not observed.

\section{Models for the Whole Factors and Complexes}

\section{TF, TF-Interacting Factors, and Their Complexes}

sTF, dcTF, and TF

Soluble TF (STF) is the extracellular domain of TF, which can be used in most cases when building a model for coagulation complexes that include TF, because the FVIIa-sTF complex is known to be enzymatically active. ${ }^{98}$ Provided that STF is an active coagulant, it can be safely assumed that the membrane-bound form of sTF should be nearly identical to that of the whole TF. An MD study reported the membrane-bound modes of free and FVIIa-bound sTF" ("Urbana-2010"). In its binary complex with FVIIa, sTF leans in a way in which the tip of the N-terminal fibronectin type III domain is lowered when compared with its free form ( - Fig. 3 ). As a result, TFmembrane lipid interaction patterns differ in the two forms. 


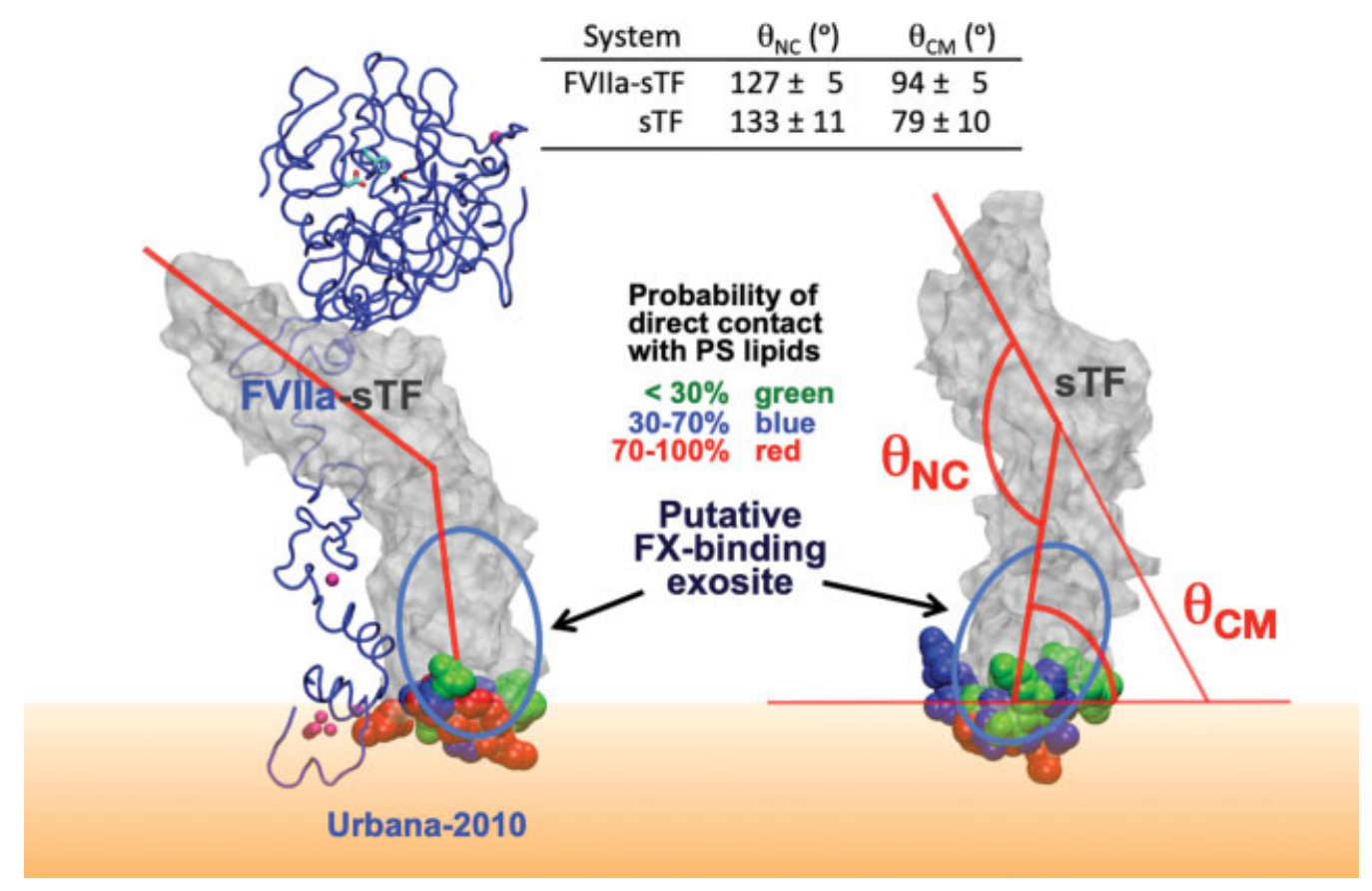

Fig. 3 Models for membrane-bound sTF both as free and FVIIa-bound forms. In "Urbana-2010," 99 FVIla-bound TF leans forward compared with isolated TF on the membrane so that the N-terminal domain of TF is lowered toward the membrane and the domain fits under the heavy chain of FVIla. Adapted from Ohkubo et $\mathrm{al}^{99}$ with permission. sTF, soluble tissue factor; TF, tissue factor.

For instance, some residues in Ser-loop of the C-terminal fibronectin type III (TFC) domain, such as K165 and K166, are significantly less interacting with membrane lipids in the FVIIa-TF complex, implying a mechanism for the preparation of the FX-binding exosite. ${ }^{17}$ The model for the whole TF including the transmembrane and cytoplasmic regions is required when studying crosstalk between coagulation and cancer-signaling cascades, in which the cytoplasmic domain of $\mathrm{TF}$ is involved. ${ }^{100}$ The model for des-cytoplasmic $\mathrm{TF}$ (dcTF ${ }^{101}$; "Chapel Hill-2012") in the binary FVIIa-dcTF complex, as well as that for the whole $\mathrm{TF}^{102}$ ("Kolkata-2018"), was proposed by other groups (see the next section). The mechanistic details of FVIIa-TF binary complex formation, however, have not been reported yet.

\section{FVIIa-TF}

A pure PS membrane-bound form of FVIIa was built, ${ }^{99}$ aligning the FVIIa part of PDB ID: $1 D^{3}{ }^{39}$ (with missing portions being modeled) onto the membrane-bound GLA domain. ${ }^{9}$ A membrane-bound model for the FVIIa-sTF complex on the PS membrane was also built similarly, including sTF in 1DAN ("Urbana-2010"). The membrane-bound, isolated FVIIa exhibited significant flexibility during MD simulation, fraying its serine protease (SP) domain. FVIIa in the membrane-bound FVIIa-sTF, on the other hand, was stabilized by STF, sustaining the CT in its SP domain at a certain orientation at $8.81 \pm 0.14 \mathrm{~nm}$ from the surface of the membrane. Other groups reported the CT height above phosphatidylcholine/PS 4:1 membrane by MD as $7.686 \pm 0.222 \mathrm{~nm}$ for FVIIa-dcTF ${ }^{101}$ and $8.497 \pm 0.069 \mathrm{~nm}$ for FVIIa-TF, ${ }^{102}$ respectively. These results are not in good agreement, and it is not quite clear what the origins of the differences are: the form of TF (sTF, dcTF, or TF), the lipid compositions in the membranes, or both. More specifically, do both TF form and membrane lipid composition have little influence on the membrane-binding mode of the binary complexes, or do they have offsetting effects instead? At least in these three works, the membrane-bound form of the GLA domain seems to be equivalent to one another ( - Table $\mathbf{1}$ ); if 1DAN is used as a template for the FVIIa-TF complex, assuming that TF interacts with the membrane via the tip of the TFC domain, the calcium line of the GLA domain would need to be about level near the surface of the membrane ${ }^{9}$ (-Fig. 1).

The reported CT heights measured by FRET also vary, ranging from 7.5 to $8.3 \mathrm{~nm}$ (-Table 2). One noticeable difference between the FRET-measured heights and the MD-measured ones is that the CT height tends to be shorter for FVIIa-TF by FRET, while MD measurements show the opposite trend. The larger CT height for isolated FVIIa indicates that FVIIa is more extended linearly in the absence of TF, presumably as close as possible, with little conformational variety, which seems to imply that FVIIa does not exist as isolated molecules (but as homodimers instead, for instance) on the membrane.

\section{FVIIa-sTF-FIX and FVIla-sTF-FXa}

The models for the TF-involved ternary complexes have not been developed very much, ${ }^{103}$ presumably due to the fact that the membrane-bound form of GLA domains is not quite established yet. There are only a few computational trials, and all of them primarily employed protein-docking methodologies between the FVIIa-sTF complex and FIX ("Grenoble-2002"104)/FXa ("Chapel Hill-2003"105 and "La Jolla-2003"11). As a result, the membrane is not explicitly included in these models, and one of these works indicated the putative membrane surface by a line in a side view of 


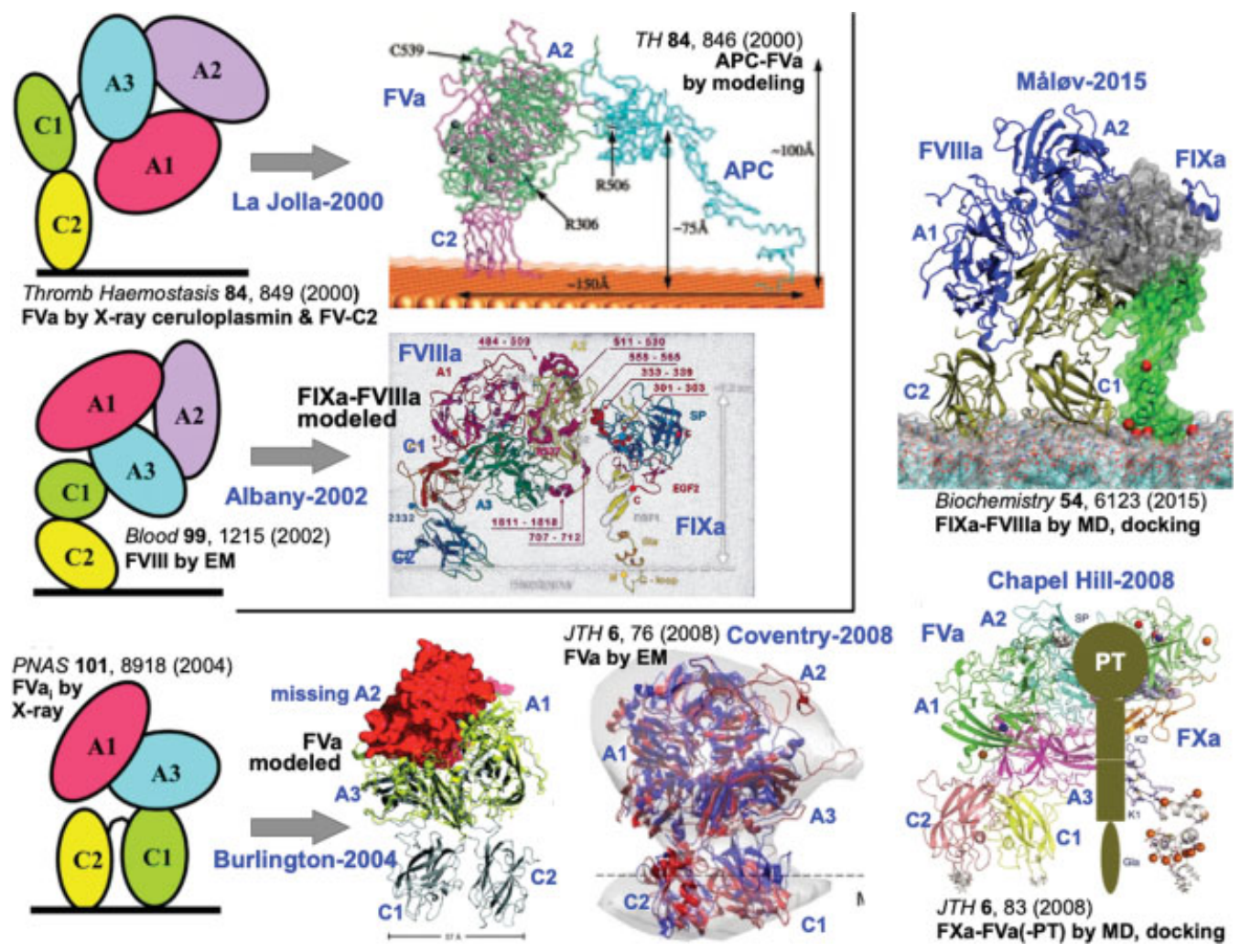

Fig. 4 Models for membrane-bound FVa and FVIII. As Adams et al ${ }^{110}$ first summarized, the membrane-bound models for FV or FVIII proposed to date can be broadly classified into three types, based on the relative position of the C1 and C2 domains: (1) the nearly inverted C1 domain is located on top of the C2 domain and the A1 domain is located closer to the membrane than the other A domains (such as "La Jolla-2000"108), (2) the $\mathrm{C} 1$ domain is on top of the $\mathrm{C} 2$ domain, with the $\mathrm{A} 3$ domain being closer to the membrane than the other A domains ("Albany-2002" 109 ), and (2) the $C 1$ and $C 2$ domains are juxtaposed, inserted to the membrane at about the same depth ("Coventry-2008," 91 "Måløv-2015" ${ }^{97}$ ). Individual figures are adapted from Stoilova-McPhie et al, ${ }^{91}$ Madsen et al, ${ }^{97}$ Pellequer et al, ${ }^{108}$ Stoilova-McPhie et al, ${ }^{109}$ Adams et al (Copyright (2004) National Academy of Sciences, U.S.A.), ${ }^{110}$ and Lee et al ${ }^{115}$ with permission.

the ternary complex model they obtained. ${ }^{104}$ In these works, the relative orientations of the FVIIa and FXa GLA domains vary (-Table 1, "Significance" column), which indicates the importance of establishing the actual membrane-bound mode of GLA domains. Again, trials for determining the configurations of membrane-bound GLA domains by the experts of SSNMR, XRR, etc. are immensely expected.

In all these models, it seems to be assumed that both GLA domains bind to the membrane, and that the domains are close to each other. As for the FVIIa-TF-FXa ternary complex, upon its engagement in TF-dependent cell signaling, however, it is proposed that the FXa GLA does not bind to the membrane but to endothelial cell protein $C$ receptor, ${ }^{106,107}$ which complicates matters further.

\section{FV, FVIII, and Their Complexes}

In the first models for the whole cofactors FVa or FVIIIa, the $\mathrm{C} 2$ domain binds to the membrane with $\mathrm{C} 1$ located on top of it, such as FVa (PDB ID: 1FV4) by modeling ${ }^{108}$ ("La Jolla2000") and FVIIIa by cryoEM ${ }^{109}$ (“Albany-2002"). Recent experiments in various conditions are, however, in accord with the juxtaposed $\mathrm{C} 1 / \mathrm{C} 2$ domains, while the membrane insertion depth of the domains remains unsettled ("Burlington-2004,"110 "Coventry-2008"91).

Activated protein C (APC)-inactivated bovine FVa (bFVa), which is missing the $\mathrm{A} 2$ domain (i.e., $\mathrm{A} 1$ and $\mathrm{A} 3-\mathrm{C} 1-\mathrm{C} 2$ ), was crystallographically determined (PDB ID: 1 SDD). ${ }^{110}$ In this work, A domains (A1, A2, and A3) were modeled from those of human $\mathrm{FV}^{111}$ and then combined with the crystal structure of bovine $\mathrm{C} 1 / \mathrm{C} 2$ domains. The A domains, therefore, have the same topology as those of FVIIIa, ${ }^{109}$ while both C1 and C2 domains bind to the membrane ( - Fig. 4). Based on this FVa model $^{110}$ and TEM studies of FVa on PS-containing lipid tubes, another model of membrane-bound $\mathrm{FVa}$, in which upright, juxtaposed $\mathrm{C} 1 / \mathrm{C} 2$ domains are half-buried into the membrane, was proposed ${ }^{91}$ (-Fig. 4).

A model for the FXa-FVa binary complex was then obtained by docking ${ }^{112}$ ("Paris-2006"), which is consistent with a site-directed mutagenesis study. ${ }^{113}$ Another group built a whole structure of FVa from the above-mentioned A2 domainless FVa model ${ }^{112}$ and homologous human ceruloplasmin (PDB ID: $1 \mathrm{KCW}^{114}$ ), equilibrated the whole FVa molecule in solution, and then performed rigid-body docking of the equilibrated FVa and FXa115 ("Chapel Hill2008"; -Fig. 4). Based on the docking results, they also 
suggested potential binding modes for the FXa-FVa-PT ternary complex.

Afterwards, the structure of FVIIIa was solved by X-ray crystallography (PDB ID: 3CDZ) with C1/C2 domains juxtaposed, as proposed by the homologous FVa. However, a slanted orientation of $\mathrm{C} 1 / \mathrm{C} 2$ domains (and therefore the whole FVIIIa as well) against the membrane was proposed, considering the interaction with FIXa, ${ }^{94}$ as opposed to the upright $\mathrm{C} 1 / \mathrm{C} 2$ domains in the membrane-bound FVa. The FRET measurement supported this slanted FVIIIa as its membrane-bound model ${ }^{96}$ ("Rochester-2013"; - Fig. 2).

Unlike GLA domains that are not in contact with the remaining part of the whole molecule, $\mathrm{C} 1 / \mathrm{C} 2$ domains are close to each other as well as to the A1 and A3 domains. It is not clear whether there is rearrangement of $\mathrm{C} 1 / \mathrm{C} 2$ domains upon membrane binding, or whether there is significant difference in $\mathrm{C} 1 / \mathrm{C} 2$ (re)arrangement between FVa and FVIIIa. For FVIII, however, a heterodimeric mode was suggested for FVIII binding to platelet-resembling LNTs (lipid nano tubes), in which FVIII binds to the membrane only by the C2 domain 22,116,117 ("Galveston-2013"). To address this flexibility issue, additional investigations should be performed.

\section{Other Relevant Targets}

Molecules whose membrane-bound modes have not been explored to a great extent include (activated) protein $C^{108,118-120}$ protein $S^{119}$ protein $Z^{121,122}$ and meizothrombin. ${ }^{123}$ The structures of these GLA domain-containing proteins are partly available, and a few models have been proposed, ${ }^{121,122}$ often together with protein $\mathrm{Z}$ inhibitor. $^{121,122,124}$ The CT heights of APC ${ }^{118-120}$ and meizothrombin $^{123}$ have been measured by FRET. As for TF pathway inhibitor $^{125,126}$ and polyphosphate, ${ }^{127,128}$ the modeling of the complexes of these molecules and other membranebound coagulants or cofactors is still to be performed. Protease activated receptor 2 (PAR2) is found to be proteolytically activated by the FVIIa-TF and FVIIa-TF-FXa complexes. ${ }^{129}$ Recently, the structures of PAR2, ${ }^{130}$ as well as of the homologous protease activated receptor $1,{ }^{131}$ in a complex form were solved by X-ray crystallography, making computational modeling and simulations feasible.

\section{Summary of Experimental and Computational Models}

As discussed in the previous sections, experimental and computational approaches to membrane-bound forms of coagulation factors are mutually complementary and evocative. For GLA domains, the experimental ${ }^{71-73}$ and computational $^{9,67,132}$ models seem to match relatively well, assuming that the bound form would be equivalent among different factors as a whole or isolated GLA domains only, due to the presumably flexible connection between the GLA and EGF1 domains. ${ }^{41,133}$ Different insertion depths of the $\omega$-loop, however, have been suggested (-Fig. 1), and direct experimental validation is needed.
The flexible GLA-EGF1 connection makes modeling of whole GLA-containing factors, especially $\operatorname{PrC}, 108$ FIXa, ${ }^{94,97,134}$ and FXa, ${ }^{112,115,135}$ difficult when they form complexes (-Fig. 4). 1 PFX $^{40}$-based structures are used in their computational models, but it is not quite clear that the factors are really in (the neighborhood of) the 1PFX conformation. Simple MD or adaptive docking methods to seek for potentially more feasible structures are time-consuming, and any other effectual attempts have not been made either experimentally or computationally to our knowledge. As for FVIIa, there are ample experimental and computational data on the CT height from the membrane surface (-Table 2), which exhibit the opposite trends on the height change upon TF binding, hypothesizing potential modes of membrane-bound FVIIa as discussed above.

As for $\mathrm{C} 1 / \mathrm{C} 2$ domains, the experimental models ${ }^{85,86,91,94,96}$ do not match well with regard to both the insertion depth and the tilt angle, while a few computational models suggest the upright $\beta$-barrel orientation with different insertion depths (-Fig. 2). The interactions between the domains and membrane lipids therefore do not match as well. Besides, it is not clear whether $\mathrm{C} 1 / \mathrm{C} 2$ domains are reoriented upon membrane binding, with respect to the membrane, as well as to the whole factors, which is not explored computationally yet due to the large sizes of FV and FVIII. TF, dcTF, and sTF are assumed to hold the upright orientation in the computational models, ${ }^{99,101,102,104}$ as experimental data indicate, ${ }^{136,137}$ in conjunction with the $1 \mathrm{DAN}^{39}$ structure. There may be reorientation of TF upon binding to FVIIa so that TF becomes available for FX binding at its exosite ( $\mathbf{- F i g . 3}$ ), but this remains largely unclear.

For the binary and tertiary complexes, data with explicit information about the membrane is mostly lacking, because the models for the complexes require in general the model for individual factors, to which solid models for membranebound GLA or C1/C2 domains are prerequisite. Alternatively, the opposite approach may be taken, in which the interactions between CT and the substrate (and the vicinity of them) are first sought (computationally) $14,115,135,138$ as the restricting factors to possible membrane-bound forms of GLA and C1/C2 domains.

\section{Future Directions and Concluding Remarks}

Since models for the membrane-bound C2 and GLA domains were first suggested in 1998 and 1999, respectively, several membrane-bound models of individual coagulation proteins and complexes have been proposed based on experimental observation. The models provide unique insights into the spatiotemporal activation, amplification, and regulation of the enzymatic cascade governing blood coagulation that ensures a proper physiological response to tissue trauma. The central balance between hemorrhage and thrombosis is determined by the precise regulation of the clotting processes under healthy conditions. In addition, lessons learnt here have immediate consequences for several hereditary diseases (notably bleeding disorders such as hemophilia) as they facilitate the rational design of coagulation-factor-based 
therapeutic strategies. This review has outlined the current state of knowledge on structural features on how exactly the activated coagulation factors interact with their primary cofactor-the membrane surface itself.

Recent development of membrane models with highmobility lipids and the application of GPUs to MD computation enable computational approaches to provide clearer views on the membrane-bound coagulation factors with atomic details and dynamics which, in turn, illuminate the molecular basis of hemostasis. Reliable membrane-bound models will help to locate key residue interactions in or around the active sites or exosites upon complex formation on the surface of the membrane that can serve as candidates for mutagenesis and conceptual design of replacement therapies. On a fundamental level, we have seen how the theoretical models for GLA domains and those for TF-involved complexes match relatively well their experimental counterparts, and further validation by the experiments is desired. The models for FV- or FVIII-involved complexes, on the other hand, exhibit a large (but intriguing!) variation to one another, and more computational trials for different environmental conditions are expected to assist the experimental ones in fully elucidating the structural and dynamic determinants of the essential molecules that help provide proper hemostasis.

\section{Funding}

This work was supported in part by Abdullah Gül Üniversitesi Bilimsel Araştırma Projeleri (TSA-2017-90 to Y.Z.O.).

\section{Conflict of Interest}

None declared.

\section{Acknowledgments}

We are grateful to Drs. Ole H. Olsen and Egon Persson for helpful discussions.

\section{References}

1 Furie B, Furie BC. The molecular basis of blood coagulation. Cell 1988;53(04):505-518

2 Furie B, Furie BC. Mechanisms of thrombus formation. N Engl J Med 2008;359(09):938-949

3 Smith SA, Travers RJ, Morrissey JH. How it all starts: initiation of the clotting cascade. Crit Rev Biochem Mol Biol 2015;50(04): 326-336

4 Morrissey JH, Davis-Harrison RL, Tavoosi N, et al. Protein-phospholipid interactions in blood clotting. Thromb Res 2010;125 (Suppl 1):S23-S25

5 Cho W, Stahelin RV. Membrane-protein interactions in cell signaling and membrane trafficking. Annu Rev Biophys Biomol Struct 2005;34:119-151

6 Lomize AL, Pogozheva ID, Lomize MA, Mosberg HI. The role of hydrophobic interactions in positioning of peripheral proteins in membranes. BMC Struct Biol 2007;7:44

7 Pellequer J-L, Gale AJ, Griffin JH, Getzoff ED. Homology models of the $C$ domains of blood coagulation factors V and VIII: a proposed membrane binding mode for FV and FVIII C2 domains. Blood Cells Mol Dis 1998;24(04):448-461

8 Venkateswarlu D, Perera L, Darden T, Pedersen LG. Structure and dynamics of zymogen human blood coagulation factor X. Biophys J 2002;82(03):1190-1206
9 Ohkubo YZ, Tajkhorshid E. Distinct structural and adhesive roles of $\mathrm{Ca}^{2+}$ in membrane binding of blood coagulation factors. Structure 2008;16(01):72-81

10 Madsen JJ, Persson E, Olsen $\mathrm{OH}$. Tissue factor activates allosteric networks in factor VIIa through structural and dynamic changes. J Thromb Haemost 2015;13(02):262-267

11 Norledge BV, Petrovan RJ, Ruf W, Olson AJ. The tissue factor/ factor VIIa/factor Xa complex: a model built by docking and sitedirected mutagenesis. Proteins 2003;53(03):640-648

12 Manna D, Bhardwaj N, Vora MS, Stahelin RV, Lu H, Cho W. Differential roles of phosphatidylserine, $\operatorname{PtdIns}(4,5) \mathrm{P}_{2}$, and $\operatorname{PtdIns}(3,4,5) \mathrm{P}_{3}$ in plasma membrane targeting of $\mathrm{C} 2$ domains. Molecular dynamics simulation, membrane binding, and cell translocation studies of the PKC $\alpha$ C2 domain. J Biol Chem 2008; 283(38):26047-26058

13 Forneris F, Burnley BT, Gros P. Ensemble refinement shows conformational flexibility in crystal structures of human complement factor D. Acta Crystallogr D Biol Crystallogr 2014;70(Pt 3):733-743

14 Sorensen AB, Madsen JJ, Frimurer TM, et al. Allostery in coagulation factor VIIa revealed by ensemble refinement of crystallographic structures. Biophys J 2019;116(10):1823-1835

15 Kirchhofer D, Lipari MT, Moran P, Eigenbrot C, Kelley RF. The tissue factor region that interacts with substrates factor IX and Factor X. Biochemistry 2000;39(25):7380-7387

16 Carlsson K, Freskgård P-O, Persson E, Carlsson U, Svensson M. Probing the interface between factor Xa and tissue factor in the quaternary complex tissue factor-factor VIla-factor Xa-tissue factor pathway inhibitor. Eur J Biochem 2003;270(12): 2576-2582

17 Ke K, Yuan J, Morrissey JH. Tissue factor residues that putatively interact with membrane phospholipids. PLoS One 2014;9(02): e88675

18 McLean MA, Gregory MC, Sligar SG. Nanodiscs: A controlled bilayer surface for the study of membrane proteins. Annu Rev Biophys 2018;47:107-124

19 Goodsell D. PDB-101 Molecule of the Month, September 2019: Nanodiscs and HDL. Accessed December 1, 2020 at: https:// pdb101.rcsb.org/motm/237

20 Kohout SC, Corbalán-García S, Gómez-Fernández JC, Falke JJ. C2 domain of protein kinase $\mathrm{C} \alpha$ : elucidation of the membrane docking surface by site-directed fluorescence and spin labeling. Biochemistry 2003;42(05):1254-1265

21 Tavoosi N, Smith SA, Davis-Harrison RL, Morrissey JH. Factor VII and protein $C$ are phosphatidic acid-binding proteins. Biochemistry 2013;52(33):5545-5552

22 Stoilova-McPhie S. Lipid nanotechnologies for structural studies of membrane-associated clotting proteins by cryo-electron microscopy. Nanotechnol Rev 2017;6(01):127-137

23 Chen C-H, Málková Š, Cho W, Schlossman ML. Configuration of membrane-bound proteins by X-ray reflectivity. J Appl Phys 2011;110(10):1-4

24 Chen C-H, Málková S, Pingali SV, et al. Configuration of PKCalphaC2 domain bound to mixed SOPC/SOPS lipid monolayers. Biophys J 2009;97(10):2794-2802

25 Johansson LC, Stauch B, Ishchenko A, Cherezov V. A bright future for serial femtosecond crystallography with XFELs. Trends Biochem Sci 2017;42(09):749-762

26 Persson E, Kjalke M, Olsen OH. Rational design of coagulation factor VIIa variants with substantially increased intrinsic activity. Proc Natl Acad Sci U S A 2001;98(24): 13583-13588

27 Hoffman M, Colina CM, McDonald AG, Arepally GM, Pedersen L, Monroe DM. Tissue factor around dermal vessels has bound factor VII in the absence of injury. J Thromb Haemost 2007;5 (07):1403-1408

28 Olsen OH, Rand KD, Østergaard H, Persson E. A combined structural dynamics approach identifies a putative switch in 
factor VIIa employed by tissue factor to initiate blood coagulation. Protein Sci 2007;16(04):671-682

29 Boettcher JM, Davis-Harrison RL, Clay MC, et al. Atomic view of calcium-induced clustering of phosphatidylserine in mixed lipid bilayers. Biochemistry 2011;50(12):2264-2273

30 Tavoosi N, Davis-Harrison RL, Pogorelov TV, et al. Molecular determinants of phospholipid synergy in blood clotting. J Biol Chem 2011;286(26):23247-23253

31 Sorensen AB, Madsen JJ, Svensson LA, et al. Molecular basis of enhanced activity in factor VIla-trypsin variants conveys insights into tissue factor-mediated allosteric regulation of factor VIla activity. J Biol Chem 2016;291(09):4671-4683

32 Nielsen AL, Sorensen AB, Holmberg HL, et al. Engineering of a membrane-triggered activity switch in coagulation factor VIla. Proc Natl Acad Sci U S A 2017;114(47):12454-12459

33 Villoutreix BO, Miteva MA. Discoidin domains as emerging therapeutic targets. Trends Pharmacol Sci 2016;37(08):641-659

34 Horava SD, Peppas NA. Recent advances in hemophilia B therapy. Drug Deliv Transl Res 2017;7(03):359-371

35 Dror RO, Dirks RM, Grossman JP, Xu H, Shaw DE. Biomolecular simulation: a computational microscope for molecular biology. Annu Rev Biophys 2012;41(01):429-452

36 Leach AR. Molecular Modelling: Principles and Applications. 2nd ed. Harlow: Pearson; 2001

37 Schlick T. Molecular Modeling and Simulation: An Interdisciplinary Guide. 2nd ed. New York, NY: Springer; 2010

38 Berman HM, Westbrook J, Feng Z, et al. The Protein Data Bank. Nucleic Acids Res 2000;28(01):235-242

39 Banner DW, D'Arcy A, Chène $C$, et al. The crystal structure of the complex of blood coagulation factor VIIa with soluble tissue factor. Nature 1996;380(6569):41-46

40 Brandstetter H, Bauer M, Huber R, Lollar P, Bode W. X-ray structure of clotting factor IXa: active site and module structure related to Xase activity and hemophilia B. Proc Natl Acad Sci U S A 1995;92(21):9796-9800

41 Pike ACW, Brzozowski AM, Roberts SM, Olsen OH, Persson E. Structure of human factor VIla and its implications for the triggering of blood coagulation. Proc Natl Acad Sci U S A 1999; 96(16):8925-8930

42 Loschwitz J, Olubiyi OO, Hub JS, Strodel B, Poojari CS. Computer simulations of protein-membrane systems. Prog Mol Biol Transl Sci 2020;170:273-403

43 Case DA, Cheatham TE III, Darden T, et al. The Amber biomolecular simulation programs. J Comput Chem 2005;26(16):1668-1688

44 Brooks BR, Brooks CL III, Mackerell AD Jr, et al. CHARMM: the biomolecular simulation program. J Comput Chem 2009;30(10): 1545-1614

45 Abraham MJ, Murtola T, Schulz R, et al. GROMACS: high performance molecular simulations through multi-level parallelism from laptops to supercomputers. SoftwareX 2015;1-2:19-25

46 Phillips JC, Braun R, Wang W, et al. Scalable molecular dynamics with NAMD. J Comput Chem 2005;26(16):1781-1802

47 Lagardère L, Jolly L-H, Lipparini F, et al. Tinker-HP: a massively parallel molecular dynamics package for multiscale simulations of large complex systems with advanced point dipole polarizable force fields. Chem Sci (Camb) 2017;9(04):956-972

48 Eastman P, Friedrichs MS, Chodera JD, et al. OpenMM 4: a reusable, extensible, hardware independent library for high performance molecular simulation. J Chem Theory Comput 2013;9(01):461-469

49 Kobayashi C, Jung J, Matsunaga Y, et al. GENESIS 1.1: a hybridparallel molecular dynamics simulator with enhanced sampling algorithms on multiple computational platforms. J Comput Chem 2017;38(25):2193-2206

50 Jorgensen WL, Maxwell DS, Tirado-Rives J. Development and testing of the OPLS all-atom force field on conformational energetics and properties of organic liquids. J Am Chem Soc 1996;118(45):11225-11236
51 McCammon JA, Harvey SC. Dynamics of Proteins and Nucleic Acids. Cambridge: Cambridge University Press; 1987

52 Brooks CL, Karplus M, Pettitt BM. Proteins: A Theoretical Perspective of Dynamics, Structure, and Thermodynamics. New York, NY: John Wiley \& Sons; 1988

53 Frenkel D, Smit B. Understanding Molecular Simulation from Algorithms to Applications. San Diego, CA: Academic Press; 2002

54 Lee J, Cheng X, Swails JM, et al. CHARMM-GUI input generator for NAMD, GROMACS, AMBER, OpenMM, and CHARMM/OpenMM simulations using the CHARMM36 additive force field. J Chem Theory Comput 2016;12(01):405-413

55 Schrodinger LLC. The PyMOL Molecular Graphics System, Version 2.4. Accessed September 10, 2020 at: https://pymol.org

56 Pettersen EF, Goddard TD, Huang CC, et al. UCSF Chimera-a visualization system for exploratory research and analysis. J Comput Chem 2004;25(13):1605-1612

57 Humphrey W, Dalke A, Schulten K. VMD: visual molecular dynamics. J Mol Graph 1996;14(01):33-38, 27-28

58 Ohkubo YZ, Thorpe IF. Evaluating the conformational entropy of macromolecules using an energy decomposition approach. J Chem Phys 2006;124(02):024910

59 Marrink SJ, Corradi V, Souza PCT, Ingólfsson HI, Tieleman DP, Sansom MSP. Computational modeling of realistic cell membranes. Chem Rev 2019;119(09):6184-6226

60 Lyubartsev AP, Rabinovich AL. Force field development for lipid membrane simulations. Biochim Biophys Acta 2016;1858(10): 2483-2497

61 Marrink SJ, Risselada HJ, Yefimov S, Tieleman DP, de Vries AH. The MARTINI force field: coarse grained model for biomolecular simulations. J Phys Chem B 2007;111(27):7812-7824

62 Enkavi G, Javanainen M, Kulig W, Róg T, Vattulainen I. Multiscale simulations of biological membranes: the challenge to understand biological phenomena in a living substance. Chem Rev 2019;119(09):5607-5774

63 Jagger BR, Kochanek SE, Haldar S, Amaro RE, Mulholland AJ. Multiscale simulation approaches to modeling drug-protein binding. Curr Opin Struct Biol 2020;61:213-221

64 Izvekov S, Voth GA. A multiscale coarse-graining method for biomolecular systems. J Phys Chem B 2005;109(07):24692473

65 Noid WG, Chu J-W, Ayton GS, et al. The multiscale coarsegraining method. I. A rigorous bridge between atomistic and coarse-grained models. J Chem Phys 2008;128(24):244114

66 Rzepiela AJ, Schäfer LV, Goga N, Risselada HJ, De Vries AH, Marrink SJ. Reconstruction of atomistic details from coarse-grained structures. J Comput Chem 2010;31(06): 1333-1343

67 Ohkubo YZ, Pogorelov TV, Arcario MJ, Christensen GA, Tajkhorshid E. Accelerating membrane insertion of peripheral proteins with a novel membrane mimetic model. Biophys J 2012;102(09): 2130-2139

68 Falcón-González JM, Jiménez-Domínguez G, Ortega-Blake I, Carrillo-Tripp M. Multi-phase solvation model for biological membranes: molecular action mechanism of amphotericin B. J Chem Theory Comput 2017;13(07):3388-3397

69 Nelsestuen GL. Enhancement of vitamin-K-dependent protein function by modification of the $\gamma$-carboxyglutamic acid domain: studies of protein C and factor VII. Trends Cardiovasc Med 1999;9 (06):162-167

70 Soriano-Garcia M, Padmanabhan K, de Vos AM, Tulinsky A. The $\mathrm{Ca}^{2+}$ ion and membrane binding structure of the Gla domain of Ca-prothrombin fragment 1. Biochemistry 1992;31(09): 2554-2566

71 Mizuno H, Fujimoto Z, Atoda H, Morita T. Crystal structure of an anticoagulant protein in complex with the Gla domain of factor X. Proc Natl Acad Sci U S A 2001;98(13):7230-7234

72 Falls LA, Furie BC, Jacobs M, Furie B, Rigby AC. The $\omega$-loop region of the human prothrombin $\gamma$-carboxyglutamic acid domain 
penetrates anionic phospholipid membranes. J Biol Chem 2001 276(26):23895-23902

73 Huang M, Rigby AC, Morelli X, et al. Structural basis of membrane binding by Gla domains of vitamin K-dependent proteins. Nat Struct Biol 2003;10(09):751-756

74 Grant MA, Baikeev RF, Gilbert GE, Rigby AC. Lysine 5 and phenylalanine 9 of the factor IX $\omega$-loop interact with phosphatidylserine in a membrane-mimetic environment. Biochemistry 2004;43(49):15367-15378

75 Lemmon MA. Membrane recognition by phospholipid-binding domains. Nat Rev Mol Cell Biol 2008;9(02):99-111

76 Zwaal RFA, Comfurius P, Bevers EM. Lipid-protein interactions in blood coagulation. Biochim Biophys Acta 1998;1376(03):433-453

77 Stace CL, Ktistakis NT. Phosphatidic acid- and phosphatidylserine-binding proteins. Biochim Biophys Acta 2006;1761(08): 913-926

78 Lin L, Huai Q Huang M, Furie B, Furie BC. Crystal structure of the bovine lactadherin $\mathrm{C} 2$ domain, a membrane binding motif, shows similarity to the $\mathrm{C} 2$ domains of factor $\mathrm{V}$ and factor VIII. J Mol Biol 2007;371(03):717-724

79 Shao C, Novakovic VA, Head JF, Seaton BA, Gilbert GE. Crystal structure of lactadherin $\mathrm{C} 2$ domain at $1.7 \mathrm{~A}$ resolution with mutational and computational analyses of its membrane-binding motif. J Biol Chem 2008;283(11):7230-7241

80 Verdaguer N, Corbalan-Garcia S, Ochoa WF, Fita I, Gómez-Fernández JC. $\mathrm{Ca}^{2+}$ bridges the $\mathrm{C} 2$ membrane-binding domain of protein kinase Calpha directly to phosphatidylserine. EMBO J 1999;18(22):6329-6338

81 Yang Y, Shu C, Li P, Igumenova TI. Structural basis of protein kinase $\mathrm{C} \alpha$ regulation by the C-terminal tail. Biophys J 2018;114 (07):1590-1603

82 Lü J, Pipe SW, Miao H, Jacquemin M, Gilbert GE. A membraneinteractive surface on the factor VIII C1 domain cooperates with the C2 domain for cofactor function. Blood 2011;117(11): 3181-3189

83 Bardelle C, Furie B, Furie BC, Gilbert GE. Membrane binding kinetics of factor VIII indicate a complex binding process. J Biol Chem 1993;268(12):8815-8824

84 Novakovic VA, Cullinan DB, Wakabayashi H, Fay PJ, Baleja JD, Gilbert GE. Membrane-binding properties of the Factor VIII C2 domain. Biochem J 2011;435(01):187-196

85 Macedo-Ribeiro S, Bode W, Huber R, et al. Crystal structures of the membrane-binding $\mathrm{C} 2$ domain of human coagulation factor V. Nature 1999;402(6760):434-439

86 Pratt KP, Shen BW, Takeshima K, Davie EW, Fujikawa K, Stoddard BL. Structure of the C2 domain of human factor VIII at $1.5 \mathrm{~A}$ resolution. Nature 1999;402(6760):439-442

87 Mertens K, Meijer AB. Factors VIII and V swap fatty feet. Blood 2012;120(09):1761-1763

88 Kim SW, Quinn-Allen MA, Camp JT, et al. Identification of functionally important amino acid residues within the C2-domain of human factor $\mathrm{V}$ using alanine-scanning mutagenesis. Biochemistry 2000;39(08):1951-1958

89 Mollica L, Fraternali F, Musco G. Interactions of the C2 domain of human factor V with a model membrane. Proteins 2006;64(02): 363-375

90 Wu S, Lee CJ, Pedersen LG. Conformational change path between closed and open forms of $\mathrm{C} 2$ domain of coagulation factor $\mathrm{V}$ on a two-dimensional free-energy surface. Phys Rev E Stat Nonlin Soft Matter Phys 2009;79(4, Pt 1):041909

91 Stoilova-McPhie S, Parmenter CDJ, Segers K, Villoutreix BO, Nicolaes GAF. Defining the structure of membrane-bound human blood coagulation factor Va. J Thromb Haemost 2008;6(01): 76-82

92 Shen BW, Spiegel PC, Chang C-H, et al. The tertiary structure and domain organization of coagulation factor VIII. Blood 2008;111 (03):1240-1247
93 Smith IW, d'Aquino AE, Coyle CW, et al. The 3.2 Å structure of a bioengineered variant of blood coagulation factor VIII indicates two conformations of the C2 domain. J Thromb Haemost 2020; 18(01):57-69

94 Ngo JCK, Huang M, Roth DA, Furie BC, Furie B. Crystal structure of human factor VIII: implications for the formation of the factor IXa-factor VIIIa complex. Structure 2008;16(04):597-606

95 Svensson LA, Thim L, Olsen OH, Nicolaisen EM. Evaluation of the metal binding sites in a recombinant coagulation factor VIII identifies two sites with unique metal binding properties. Biol Chem 2013;394(06):761-765

96 Wakabayashi H, Fay PJ. Molecular orientation of Factor VIIIa on the phospholipid membrane surface determined by fluorescence resonance energy transfer. Biochem J 2013;452(02):293-301

97 Madsen JJ, Ohkubo YZ, Peters GH, Faber JH, Tajkhorshid E, Olsen $\mathrm{OH}$. Membrane interaction of the factor VIIIa discoidin domains in atomistic detail. Biochemistry 2015;54(39):6123-6131

98 Neuenschwander PF, Bianco-Fisher E, Rezaie AR, Morrissey JH. Phosphatidylethanolamine augments factor VIIa-tissue factor activity: enhancement of sensitivity to phosphatidylserine. Biochemistry 1995;34(43):13988-13993

99 Ohkubo YZ, Morrissey JH, Tajkhorshid E. Dynamical view of membrane binding and complex formation of human factor VIla and tissue factor. J Thromb Haemost 2010;8(05):1044-1053

100 Versteeg HH, Schaffner F, Kerver M, et al. Inhibition of tissue factor signaling suppresses tumor growth. Blood 2008;111(01): 190-199

101 Lee CJ, Wu S, Bartolotti LJ, Pedersen LG. Molecular dynamic simulations of the binary complex of human tissue factor $\left(\mathrm{TF}_{1-242}\right)$ and factor VIIa $\left(\mathrm{TF}_{1-242} / \mathrm{FVIIa}\right)$ on a 4:1 POPC/POPS lipid bilayer. J Thromb Haemost 2012;10(11):2402-2405

102 Prasad R, Sen P. Structural modulation of factor VIIa by fulllength tissue factor $\left(\mathrm{TF}_{1-263}\right)$ : implication of novel interactions between EGF2 domain and TF. J Biomol Struct Dyn 2018;36(03): 621-633

103 Vadivel K, Bajaj SP. Structural biology of factor VIIa/tissue factor initiated coagulation. Front Biosci 2012;17(07):2476-2494

104 Chen S-WW, Pellequer J-L, Schved J-F, Giansily-Blaizot M. Model of a ternary complex between activated factor VII, tissue factor and factor IX. Thromb Haemost 2002;88(01):74-82

105 Venkateswarlu D, Duke RE, Perera L, Darden TA, Pedersen LG. An all-atom solution-equilibrated model for human extrinsic blood coagulation complex (sTF-VIIa-Xa): a protein-protein docking and molecular dynamics refinement study. J Thromb Haemost 2003;1(12):2577-2588

106 Disse J, Petersen HH, Larsen KS, et al. The endothelial protein C receptor supports tissue factor ternary coagulation initiation complex signaling through protease-activated receptors. J Biol Chem 2011;286(07):5756-5767

107 Ruf W, Disse J, Carneiro-Lobo TC, Yokota N, Schaffner F. Tissue factor and cell signalling in cancer progression and thrombosis. J Thromb Haemost 2011;9(Suppl 1):306-315

108 Pellequer J-L, Gale AJ, Getzoff ED, Griffin JH. Three-dimensional model of coagulation factor Va bound to activated protein $C$. Thromb Haemost 2000;84(05):849-857

109 Stoilova-McPhie S, Villoutreix BO, Mertens K, Kemball-Cook G, Holzenburg A. 3-Dimensional structure of membrane-bound coagulation factor VIII: modeling of the factor VIII heterodimer within a 3-dimensional density map derived by electron crystallography. Blood 2002;99(04):1215-1223

110 Adams TE, Hockin MF, Mann KG, Everse SJ. The crystal structure of activated protein C-inactivated bovine factor Va: Implications for cofactor function. Proc Natl Acad Sci U S A 2004;101(24): 8918-8923

111 Villoutreix BO, Dahlbäck B. Structural investigation of the A domains of human blood coagulation factor $\mathrm{V}$ by molecular modeling. Protein Sci 1998;7(06):1317-1325 
112 Autin L, Steen M, Dahlbäck B, Villoutreix BO. Proposed structural models of the prothrombinase (FXa-FVa) complex. Proteins 2006;63(03):440-450

113 Steen M, Tran S, Autin L, Villoutreix BO, Tholander A-L, Dahlbäck B. Mapping of the factor Xa binding site on factor Va by sitedirected mutagenesis. J Biol Chem 2008;283(30):20805-20812

114 Zaitseva I, Zaitsev V, Card G, et al. The X-ray structure of human serum ceruloplasmin at $3.1 \AA$ : nature of the copper centres. J Biol Inorg Chem 1996;1(01):15-23

115 Lee CJ, Lin P, Chandrasekaran V, et al. Proposed structural models of human factor Va and prothrombinase. J Thromb Haemost 2008;6(01):83-89

116 Stoilova-McPhie S, Lynch GC, Ludtke S, Pettitt BM. Domain organization of membrane-bound factor VIII. Biopolymers 2013;99(07):448-459

117 Dalm D, Galaz-Montoya JG, Miller JL, et al. Dimeric organization of blood coagulation factor VIII bound to lipid nanotubes. Sci Rep 2015;5:11212

118 Perera L, Foley C, Darden TA, et al. Modeling zymogen protein C. Biophys J 2000;79(06):2925-2943

119 Yegneswaran S, Wood GM, Esmon CT, Johnson AE. Protein S alters the active site location of activated protein $C$ above the membrane surface. A fluorescence resonance energy transfer study of topography. J Biol Chem 1997;272(40):25013-25021

120 Yegneswaran S, Smirnov MD, Safa O, Esmon NL, Esmon CT, Johnson AE. Relocating the active site of activated protein $C$ eliminates the need for its protein $S$ cofactor. A fluorescence resonance energy transfer study. J Biol Chem 1999;274(09): 5462-5468

121 Wei Z, Yan Y, Carrell RW, Zhou A. Crystal structure of protein Zdependent inhibitor complex shows how protein $Z$ functions as a cofactor in the membrane inhibition of factor X. Blood 2009;114 (17):3662-3667

122 Huang X, Dementiev A, Olson ST, Gettins PGW. Basis for the specificity and activation of the serpin protein Z-dependent proteinase inhibitor (ZPI) as an inhibitor of membrane-associated factor Xa. J Biol Chem 2010;285(26):20399-20409

123 Armstrong SA, Husten EJ, Esmon CT, Johnson AE. The active site of membrane-bound meizothrombin. A fluorescence determination of its distance from the phospholipid surface and its conformational sensitivity to calcium and factor Va. J Biol Chem 1990;265(11):6210-6218

124 Chandrasekaran V, Lee CJ, Lin P, Duke RE, Pedersen LG. A computational modeling and molecular dynamics study of the Michaelis complex of human protein Z-dependent protease inhibitor (ZPI) and factor Xa (FXa). J Mol Model 2009;15(08):897-911

125 Mast AE. Tissue factor pathway inhibitor: multiple anticoagulant activities for a single protein. Arterioscler Thromb Vasc Biol 2016;36(01):9-14

126 Chowdary P. Inhibition of tissue factor pathway inhibitor (TFPI) as a treatment for haemophilia: rationale with focus on concizumab. Drugs 2018;78(09):881-890

127 Morrissey JH, Choi SH, Smith SA. Polyphosphate: an ancient molecule that links platelets, coagulation, and inflammation. Blood 2012;119(25):5972-5979

128 Mailer RKW, Hänel L, Allende M, Renné T Polyphosphate as a target for interference with inflammation and thrombosis. Front Med (Lausanne) 2019;6:76

129 Riewald M, Ruf W. Mechanistic coupling of protease signaling and initiation of coagulation by tissue factor. Proc Natl Acad Sci U S A 2001;98(14):7742-7747

130 Cheng RKY, Fiez-Vandal C, Schlenker O, et al. Structural insight into allosteric modulation of protease-activated receptor 2 . Nature 2017;545(7652):112-115

131 Zhang C, Srinivasan Y, Arlow DH, et al. High-resolution crystal structure of human protease-activated receptor 1. Nature 2012; 492(7429):387-392
132 Muller MP, Wang Y, Morrissey JH, Tajkhorshid E. Lipid specificity of the membrane binding domain of coagulation factor X. J Thromb Haemost 2017;15(10):2005-2016

133 Persson E, Madsen JJ, Olsen OH. The length of the linker between the epidermal growth factor-like domains in factor VIIa is critical for a productive interaction with tissue factor. Protein Sci 2014; 23(12):1717-1727

134 Autin L, Miteva MA, Lee WH, Mertens K, Radtke K-P, Villoutreix BO. Molecular models of the procoagulant factor VIIla-factor IXa complex. J Thromb Haemost 2005;3(09):2044-2056

135 Lechtenberg BC, Murray-Rust TA, Johnson DJD, et al. Crystal structure of the prothrombinase complex from the venom of Pseudonaja textilis. Blood 2013;122(16):2777-2783

136 McCallum CD, Hapak RC, Neuenschwander PF, Morrissey JH, Johnson AE. The location of the active site of blood coagulation factor VIIa above the membrane surface and its reorientation upon association with tissue factor. A fluorescence energy transfer study. J Biol Chem 1996;271(45):28168-28175

137 McCallum CD, Su B, Neuenschwander PF, Morrissey JH, Johnson AE. Tissue factor positions and maintains the factor VIla active site far above the membrane surface even in the absence of the factor VIla Gla domain. A fluorescence resonance energy transfer study. J Biol Chem 1997;272(48):30160-30166

138 Lee CJ, Wu S, Pedersen LG. A proposed ternary complex model of prothrombinase with prothrombin: protein-protein docking and molecular dynamics simulations. J Thromb Haemost 2011; 9(10):2123-2126

139 Perera L, Darden TA, Pedersen LG. Modeling human zymogen factor IX. Thromb Haemost 2001;85(04):596-603

140 Orban T, Kalafatis M, Gogonea V. Completed three-dimensional model of human coagulation factor va. Molecular dynamics simulations and structural analyses. Biochemistry 2005;44 (39):13082-13090

141 Chaves RC, Dahmane S, Odorico M, Nicolaes GAF, Pellequer J-L. Factor Va alternative conformation reconstruction using atomic force microscopy. Thromb Haemost 2014;112(06):1167-1173

142 Du J, Wichapong K, Hackeng KM, Nicolaes GAF. Molecular simulation studies of human coagulation factor VIII C domain-mediated membrane binding. Thromb Haemost 2015;113(02):373-384

143 Fay PJ. Activation of factor VIII and mechanisms of cofactor action. Blood Rev 2004;18(01):1-15

144 Oslakovic C, Krisinger MJ, Andersson A, Jauhiainen M, Ehnholm C, Dahlbäck B. Anionic phospholipids lose their procoagulant properties when incorporated into high density lipoproteins. J Biol Chem 2009;284(09):5896-5904

145 Morrissey Lab, University of Michigan. X-Ray crystal structures and NMR structures of tissue factor, factor VII, factor VIIa, TFPI, and antibodies to these proteins. Accessed September 10, 2020 at: https://tf7.org/structures/

146 Colina CM, Venkateswarlu D, Duke R, Perera L, Pedersen LG. What causes the enhancement of activity of factor VIla by tissue factor? J Thromb Haemost 2006;4(12):2726-2729

147 Waters EK, Yegneswaran S, Morrissey JH. Raising the active site of factor VIIa above the membrane surface reduces its procoagulant activity but not factor VII autoactivation. J Biol Chem 2006;281(36):26062-26068

148 Mutucumarana VP, Duffy EJ, Lollar P, Johnson AE. The active site of factor IXa is located far above the membrane surface and its conformation is altered upon association with factor VIIIa. A fluorescence study. J Biol Chem 1992;267(24):17012-17021

149 Husten EJ, Esmon CT, Johnson AE. The active site of blood coagulation factor $\mathrm{Xa}$. Its distance from the phospholipid surface and its conformational sensitivity to components of the prothrombinase complex. J Biol Chem 1987;262(27):12953-12961

150 Qureshi SH, Yang L, Yegneswaran S, Rezaie AR. FRET studies with factor $\mathrm{X}$ mutants provide insight into the topography of the membrane-bound factor X/Xa. Biochem J 2007;407(03):427-433 